\title{
Avances y desafíos para la titulación de comunidades nativas en Perú
}

Perspectivas de doce comunidades en San Martín y Ucayali

Peter Cronkleton

Frangi Valencia

Joe S. Saldaña

Anne Larson 



\section{Avances y desafíos para la titulación de comunidades nativas en Perú}

Perspectivas de doce comunidades en San Martín y Ucayali

Peter Cronkleton

Frangi Valencia

Joe S. Saldaña

Anne Larson 
@ 2019 Centro para la Investigación Forestal Internacional (CIFOR)

(c) (1) Los contenidos de esta publicación están bajo licencia Creative Commons Attribution 4.0 International (CC BY 4.0), http://creativecommons.org/licenses/by/4.0/

DOI: 10.17528/cifor/007391

Cronkleton P, Valencia F, Saldaña JS, y Larson A. 2019. Avances y desafíos para la titulación de comunidades nativas en Perú: Perspectivas de doce comunidades en San Martín y Ucayali. Bogor, Indonesia: CIFOR.

Foto de portada por Marlon del Aguila Guerrero/CIFOR

Paisaje forestal en Perú

\author{
CIFOR \\ J. CIFOR, Situ Gede \\ Bogor Barat 16115 \\ Indonesia \\ $\mathrm{T}+62(251) 8622-622$ \\ $\mathrm{F}+62(251) 8622-100$ \\ E cifor@cgiar.org
}

\title{
cifor.org
}

Quisiéramos agradecer a todos los socios financieros que apoyaron esta investigación a través de sus contribuciones al Fondo de CGIAR. Para ver la lista de donantes del Fondo, visite: http://www.cgiar.org/about-us/our-funders/

Cualquier opinión vertida en este documento es de los autores. No refleja necesariamente las opiniones de CIFOR, de las instituciones para las que los autores trabajan o de los financiadores. 


\section{Contenido}

Agradecimientos $\quad$ v

1 Introducción 1

2 Antecedentes 2

3 Metodología 3

3.1 Objetivo general 3

3.2 Objetivos específicos 3

3.3 Selección de las comunidades 3

3.4 Devolución de resultados 5

4 Síntesis de los resultados $\quad 8$

4.1 La formalización y la seguridad de la tenencia de tierras 8

$\begin{array}{ll}4.2 & \text { Medios de vida } \\ & 13\end{array}$

$\begin{array}{lll}4.3 & \text { Territorio y producción } & 21\end{array}$

5 Conclusiones $\quad 29$

Referencias

Anexo 1

Especies maderables cosechadas por informantes en San Martín y Ucayali 


\section{Lista de figuras y cuadros}

\section{Figuras}

1 Mapa de ubicación de las comunidades evaluadas en la región San Martín 4

2 Mapa de ubicación de las comunidades evaluadas en la provincia de Atalaya, Ucayali 5

3 Cambios en la seguridad desde la titulación o demarcación 10

4 Usos de la tierra por las comunidades de San Martín y Ucayali 15

5 Porcentaje de hogares que realizan actividades de caza en San Martín y Ucayali $\quad 16$

6 Porcentaje de hogares que practican la pesca en San Martín y Ucayali 17

7 Utilización de productos no maderables en las regiones de San Martín y Ucayali 18

8 Situación económica de los hogares comparada con las de sus vecinos en el último año 19

9 Situación económica de los hogares por región y género 20

10 Situación económica en los últimos 5 años según el estado de la titulación 20

11 Situación económica por género en los últimos 5 años 21

12 Mapas parlantes sobre uso de la tierra realizados por comuneros y comuneras de Charapillo, San Martín 22

13 Percepciones sobre los cambios en la situación de los bosques en los últimos 20 ańos 24

14 Satisfacción de las necesidades alimentarias por región en el último año 25

15 Satisfacción de las necesidades alimentarias por género en el último año 26

16 Cambios en la seguridad alimentaria por región en los últimos 5 años 27

17 Cambios en la seguridad alimentaria por género en los últimos 5 años 27

\section{Cuadros}

1 Estado del proceso de tenencia en 12 comunidades nativas de San Martín y Ucayali 6

2 Número de personas y hogares donde se aplicaron las herramientas metodológicas en las regiones de San Martín y Ucayali

3 Zonificación de las comunidades 


\section{Agradecimientos}

Este estudio fue posible gracias al apoyo de la cooperación alemana para el desarrollo, implementada por la Deutsche Gesellschaft für Internationale Zusammenarbeit (GIZ) GmbH en el marco del proyecto ProTierras Comunales.

Los autores agradecen sinceramente a los comuneros y comuneras que participaron y colaboraron con el desarrollo de este estudio. También a las organizaciones indígenas que hicieron posible esta investigación: la Coordinadora de Desarrollo y Defensa de los Pueblos Indígenas de la Región San Martín (CODEPISAM), la Federación Kichwa Huallaga Dorado (FEKIHD), la Federación de Pueblos Indígenas Kichwas de la Región San Martín (FEPIKRESAM) y a la Federación Regional Indígena Shawi de San Martín (FERISHAM) en la región San Martín; y a la Organización Indígena Regional de Atalaya (OIRA), la Federación Asháninka del Bajo Urubamba (FABU) y la Federación de Comunidades Nativas Ashéninka de la Provincia de Atalaya (FECONAPA) en la región Ucayali.

También agradecemos al equipo de trabajo de campo conformado por Nelly Berenice Cabrera, Sandra Gonzales De la Cotera, Erik Basualdo Chávez, Milagros Castañeda Paredes, Carlos E. Llerena Malpartida y Diana Landauro Rodríguez; así como a Karin Rivera Miranda en el procesamiento de datos.

Finalmente, reconocemos a todas las personas que de una u otra manera contribuyeron con el desarrollo de este estudio. 



\section{Introducción}

El Gobierno de Perú está avanzando con el reconocimiento y formalización de los derechos territoriales de los pueblos indígenas de la Amazonía a través de, entre otros mecanismos, la titulación de tierras de las comunidades nativas (CCNN). Debido a la complejidad de este proceso, que involucra múltiples actores en diferentes niveles, resulta especialmente importante profundizar el entendimiento de cómo se lleva a cabo la titulación en las comunidades, y cómo son percibidos sus impactos por los beneficiarios.

Bajo esa premisa, y considerando la necesidad de generar información a nivel local que pueda orientar las políticas públicas, el proyecto de investigación aplicada "Titulación de Comunidades Nativas - Avances y desafíos" analizó estos procesos y sus implicaciones en doce CCNN en las regiones San Martín y Ucayali.
El estudio fue dirigido por el Centro para la Investigación Forestal Internacional (CIFOR), con el apoyo de la cooperación alemana para el desarrollo, implementada por la Deutsche Gesellschaft für Internationale Zusammenarbeit (GIZ) $G m b H$ en el marco del proyecto ProTierras Comunales, y buscó ampliar el trabajo iniciado por el Estudio Comparativo Global sobre Reformas de Tenencia en Tierras Forestales (GCS-Tenure) de CIFOR, desarrollado en las regiones de Loreto y Madre de Dios (véase http://www.cifor.org/ gcs-tenure/).

Este documento es una síntesis de los principales resultados del estudio. Además, en los casos que aplica, el informe compara estos resultados con los del estudio GCS-Tenure. 


\section{Antecedentes}

Para los más de 50 pueblos indígenas de la Amazonía peruana el reconocimiento de sus derechos territoriales es una meta central, ya que su sobrevivencia y sustento dependen de la tierra, bosques y otros recursos naturales. Desde 1974, el Gobierno peruano ha formalizado los derechos de propiedad colectiva de más de $1300 \mathrm{CCNN}$ en la Amazonía (IBC, 2016). Sin embargo, desde la aprobación de la Ley de Comunidades Nativas en 1974, diversos cambios en las políticas nacionales han influenciado este proceso (Monterroso et al. 2017). Ejemplos de estos son los cambios en la legislación forestal en 1975 que clasificó los bosques como patrimonio nacional (haciendo necesaria la distinción entre áreas de aptitud agrícola, forestal y de protección); y el impulso de la llamada descentralización administrativa desde los años 2000, que pasó la responsabilidad de la titulación a los gobiernos regionales (GORE).

Estas modificaciones en el marco regulatorio y en las responsabilidades de las instituciones involucradas, así como una falta de asignación presupuestaria, afectaron la implementación de las reformas. Por ello, quedan pendientes el reconocimiento y la titulación de muchas $\mathrm{CCNN}$, la entrega de los contratos de cesión en uso como reconocimiento de los derechos de las CCNN sobre áreas clasificadas como forestales o de protección (Monterroso et al. 2017), y el registro de muchos títulos en la Superintendencia Nacional de los Registros Públicos -SUNARP- (IBC, 2016).

A partir de 2014, el Gobierno peruano retomó los procesos de reconocimiento, titulación y ampliación ${ }^{1}$ de los territorios de las CCNN

1 Las CCNN pueden solicitar la ampliación de su territorio, si este no brinda los medios necesarios para el sustento de las familias. El proceso de ampliación sigue los mismos pasos que el de titulación. con el apoyo de la cooperación internacional y de proyectos relacionados con el cambio climático. Ese mismo ańo, el Ministerio de Agricultura y Riego (MINAGRI) asumió nuevamente el papel de ente rector para la titulación de las CCNN a través de la creación de la Dirección de Saneamiento de la Propiedad Agraria y Catastro Rural (DISPACR), la cual se convirtió en Dirección General en 2017 (DIGESPACR).

Los gobiernos regionales están a cargo de la implementación de los procesos de titulación de las CCNN, reconocidas a través de sus Direcciones Regionales Agrarias (DRA) o dependencias similares, con la participación de federaciones indígenas, diversas instituciones estatales de nivel nacional y organizaciones externas de apoyo como ONG (ver detalles de la normativa y los procesos en la práctica en Camero y Gonzales 2018 y Monterroso et al. 2019).

La titulación es un proceso sumamente importante que permite asegurar los derechos de propiedad de las CCNN en Perú, así como en otras partes del mundo. Por eso, es necesario entender el impacto del proceso de titulación en las CCNN y cómo es percibido por las familias beneficiarias. Además, como señalan otras investigaciones (Cronkleton et al. 2008; Pacheco et al 2011; Larson et al. 2019; Monterroso et al. 2019), contar con derechos de propiedad seguros produce mejoras en los sistemas productivos y en las opciones de medios de vida sostenibles, importantes para el bienestar de las personas. Para hacer seguimiento de los posibles cambios en la economía familiar y el uso de recursos naturales en los nuevos territorios titulados, es preciso contar con información que permita observar cómo estas modificaciones son percibidas por los pobladores locales. 


\section{Metodología}

El proyecto "Titulación de Comunidades Nativas

- Avances y desafíos" se ejecutó entre diciembre de 2017 y abril de 2019 en las zonas de intervención del proyecto ProTierras Comunales, en las regiones San Martín y Ucayali. Este estudio tenía por finalidad recolectar información que promueva la reflexión y el diálogo sobre el avance de los procesos de titulación de las $\mathrm{CCNN}$ y los retos que limitan su implementación. Aquí se presentan los resultados principales.

\subsection{Objetivo general}

Analizar los procesos de titulación en las comunidades nativas y su impacto en los bosques y sus habitantes en las regiones de San Martín y Ucayali, así como proporcionar información que permita evaluar y mejorar las iniciativas de titulación en curso.

\subsection{Objetivos específicos}

- Obtener y comparar las percepciones de los representantes de las CCNN sobre los procesos de titulación, en cuanto a participación comunitaria, desafíos e impacto de la titulación.

- Identificar los factores relacionados con la seguridad de tenencia de tierras y los efectos de la titulación en la mejora de esa seguridad.

- Documentar patrones de gobernanza territorial y prácticas de manejo forestal en las CCNN seleccionadas.

- Preparar una línea de base sobre los cambios producidos a consecuencia de la titulación para un análisis posterior.

\subsection{Selección de las comunidades}

Se seleccionaron seis CCNN por región, en colaboración entre CIFOR, el equipo de ProTierras Comunales y representantes de las organizaciones indígenas en las regiones estudiadas. En esta selección se tomaron en cuenta comunidades tituladas hace varias décadas, comunidades con demarcación reciente y comunidades que estaban iniciando el proceso de titulación. El proyecto también consideró criterios como la etnia de la comunidad, la existencia de conflictos, la facilidad de acceso (dado el tiempo limitado para el trabajo de campo) y la aprobación comunal para participar en el estudio.

En San Martín, las tres organizaciones indígenas que participaron en la selección de las comunidades que serían estudiadas pertenecen a la Coordinadora de Desarrollo y Defensa de Pueblos Indígenas de la Región San Martín (CODEPISAM), la que a su vez forma parte de la Asociación Interétnica de Desarrollo de la Selva Peruana (AIDESEP). Las organizaciones que colaboraron con el estudio fueron:

- La Federación de Pueblos Indígenas Kichwas de la Región San Martín (FEPIKRESAM)

- La Federación Kichwas Huallaga Dorado (FEKIHD)

- La Federación Regional Indígena Shawi de San Martín (FERISHAM)

En Ucayali, las tres organizaciones indígenas que apoyaron con la selección de comunidades fueron dos pertenecientes a la federación regional Unión Regional de los Pueblos Indígenas de la Amazonía de la Provincia de Atalaya (URPIA), 
asociada con la Confederación de Nacionalidades Amazónicas del Perú (CONAP), y otra afiliada a la federación regional Coordinadora Regional de los Pueblos Indígenas de Atalaya (CORPIAA), que forma parte de la Asociación Interétnica de Desarrollo de la Selva Peruana (AIDESEP). Estas organizaciones fueron:

- La Federación Asháninka del Bajo Urubamba (FABU)

- La Federación de Comunidades Nativas Ashéninka de la Provincia de Atalaya (FECONAPA)

- La Organización Indígena Regional de Atalaya (OIRA)

En San Martín, se seleccionaron las comunidades de Chirikyacu, Charapillo, Chirik Sacha, Santa Rosa de Alto Chambira, Juliampampa y Tornillo Yacuzelandia (Figura 1). En Ucayali, las comunidades escogidas fueron Aerija, Nueva Esperanza, Capajeriato, Tzinquiato, Inkare y
Centro Chocote (Figura 2) (véase también el Cuadro 1 que presenta una lista de las comunidades y sus características).

De las doce comunidades elegidas, dos han completado el proceso de titulación (es decir, cuentan con títulos georreferenciados e inscritos en registros públicos), seis están tituladas (pero no cuentan con límites georreferenciados o no están inscritas en registros públicos, o les faltan ambas etapas) y las otras cuatro están en proceso de titulación (han sido reconocidas por el gobierno y están siendo demarcadas, pero no han cumplido con las etapas restantes). Tres de las comunidades tituladas obtuvieron ampliaciones de sus territorios y una de ellas tiene una solicitud de ampliación en proceso. Las ampliaciones tienen por finalidad incluir áreas y recursos importantes para los medios de vida de los pobladores y asegurar esos recursos para las futuras generaciones.

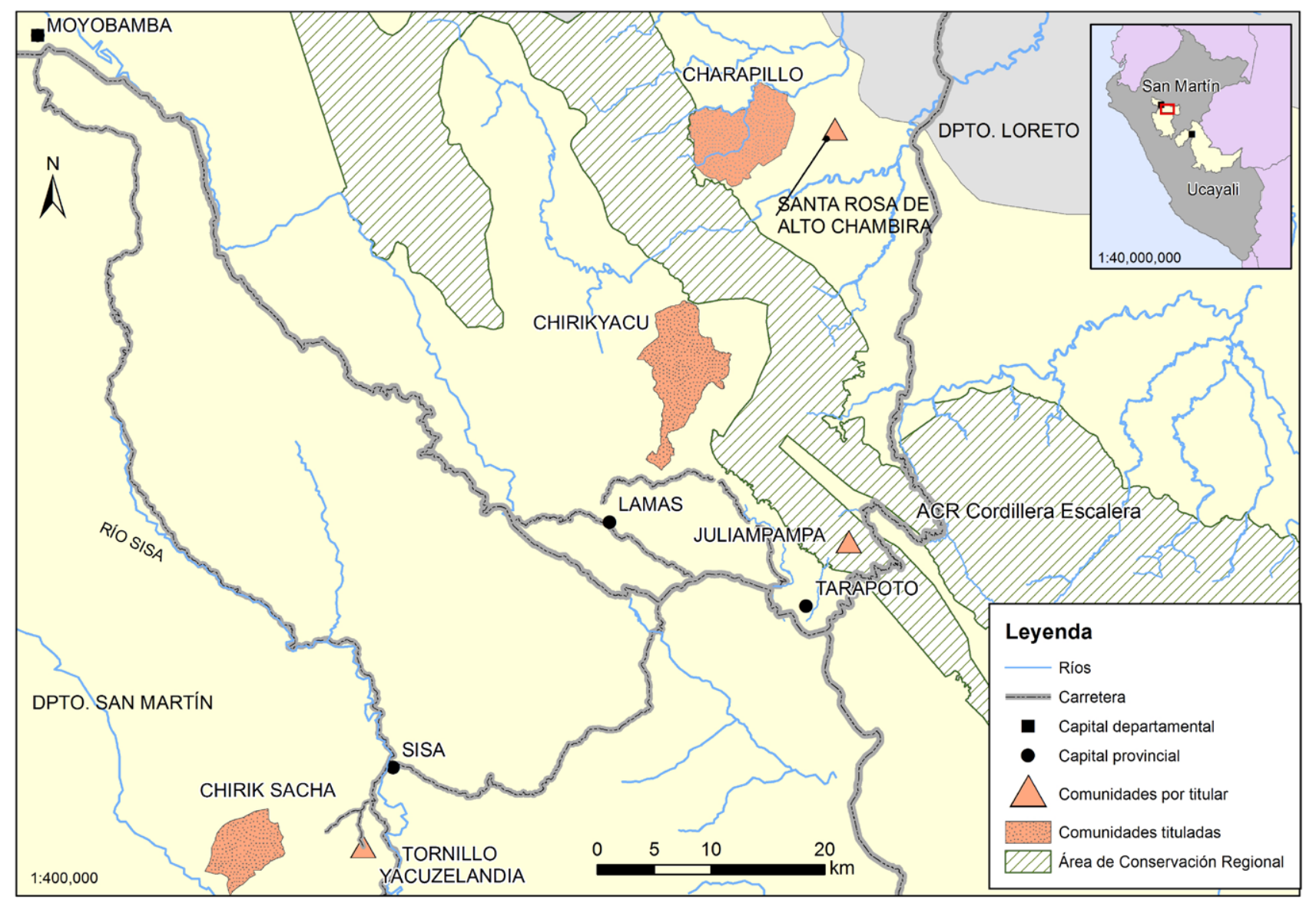

Figura 1. Mapa de ubicación de las comunidades evaluadas en la región San Martín 


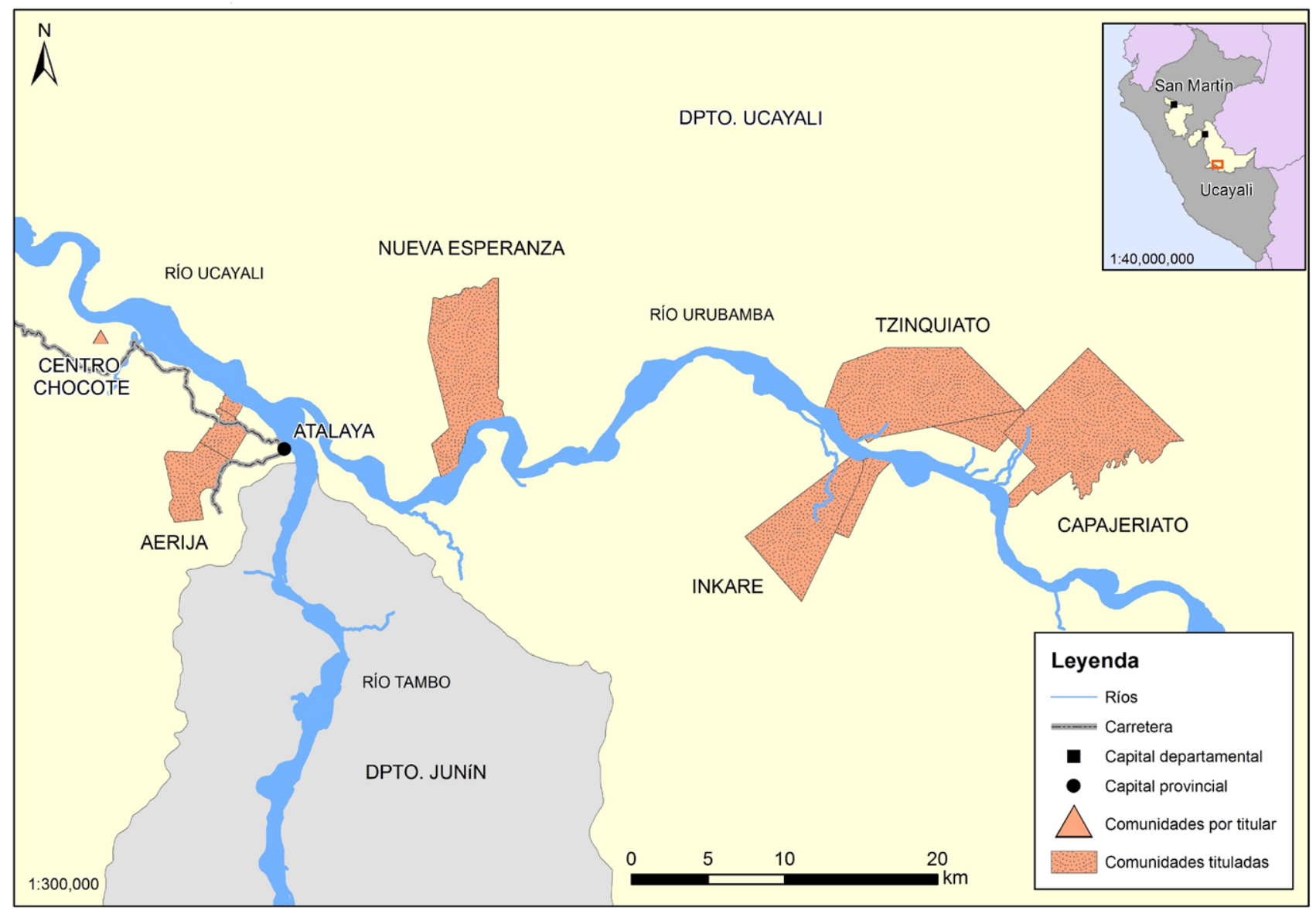

Figura 2. Mapa de ubicación de las comunidades evaluadas en la provincia de Atalaya, Ucayali

El trabajo de campo se realizó entre el 28 de febrero y el 2 de abril de 2018, con dos equipos (uno por región). Cada equipo de campo estuvo conformado por cuatro miembros, hombres y mujeres, a fin de facilitar la recolección de datos en las comunidades de intervención del proyecto.

Los equipos utilizaron los siguientes métodos para recopilar información:

- Entrevistas con informantes clave para obtener información general sobre la comunidad y sus avances en el proceso de titulación. Los participantes en estas entrevistas semiestructuradas eran líderes comunitarios (mujeres y hombres) con conocimiento del contexto local. Estas se realizaron de manera individual y en algunos casos, grupal.

- Grupos focales con hombres y mujeres líderes y miembros de la comunidad -desagregados por género- para entender sus experiencias en relación con el proceso de titulación y sus percepciones sobre la seguridad de los derechos de propiedad.
- Encuestas intrahogares para recopilar datos sobre el hogar, estrategias de medios de vida y percepciones acerca de los derechos de propiedad y su seguridad. Las encuestas se centraron en los jefes de hogar (hombres y mujeres) de familias seleccionadas aleatoriamente.

En total, los equipos entrevistaron a 62 informantes clave en ambas regiones y realizaron 24 grupos focales. Los grupos focales contaron con la participación de 284 mujeres y hombres. Para la encuesta de hogares, se definió una muestra aleatoria de 181 familias, que resultó en 338 encuestas con jefes de hogar, tanto hombres como mujeres (véase el Cuadro 2 sobre la muestra y distribución regional).

\subsection{Devolución de resultados}

La última etapa de la metodología tuvo por objetivo compartir los resultados del estudio por 
Cuadro 1. Estado del proceso de tenencia en 12 comunidades nativas de San Martín y Ucayali

\begin{tabular}{|c|c|c|c|c|c|c|c|c|}
\hline \multirow{2}{*}{$\begin{array}{l}\text { Comunidad nativa } \\
\text { (pueblo indígena) }\end{array}$} & \multicolumn{4}{|c|}{ Año } & \multirow{2}{*}{$\begin{array}{l}\text { Superficie } \\
\text { total (ha) }\end{array}$} & \multicolumn{3}{|c|}{ Estado de saneamiento } \\
\hline & Reconocimiento & Demarcación & Titulación & Ampliación & & Georreferenciada & Titulada & Inscrita en registros públicos \\
\hline \multicolumn{9}{|c|}{ Ucayali (todas Asháninka o Ashéninka) } \\
\hline Aerija & 1975 & & 1975 & 1994 & 3,092 & No & Sí & No \\
\hline Nueva Esperanza & 1987 & & 1992 & - & 4,752 & No & Sí & Sí \\
\hline Capajeriato & 1989 & 1989 & 1992 & - & 5,289 & No & Sí & Sí \\
\hline Tzinquiato & 1989 & 1988 & 1994 & 1998 & 6,717 & Sí & Sí & Sí \\
\hline Inkare & 1990 & & 1991 & 1997 & 3,785 & Sí & Sí & Sí \\
\hline Centro Chocote & 2018 & 2018 & & - & - & Sí & No & No \\
\hline \multicolumn{9}{|l|}{ San Martín } \\
\hline Chirikyacu (Kichwa) & 1997 & 1997 & 1997 & - & 5,492 & Sí & Sí & No \\
\hline Charapillo (Shawi) & 1997 & 1997 & 1997 & En proceso & 4,166 & Sí & Sí & No \\
\hline $\begin{array}{l}\text { Chirik Sacha } \\
\text { (Kichwa) }\end{array}$ & 1997 & 1997 & 1997 & - & 3,755 & Sí & Sí & No \\
\hline $\begin{array}{l}\text { Santa Rosa de Alto } \\
\text { Chambira (Shawi) }\end{array}$ & 2013 & 2017 & En proceso & - & - & En proceso & No & No \\
\hline $\begin{array}{l}\text { Tornillo Yacuzelandia } \\
\text { (Kichwa) }\end{array}$ & 2016 & 2018 & En proceso & - & - & En proceso & No & No \\
\hline $\begin{array}{l}\text { Juliampampa } \\
\text { (Kichwa) }\end{array}$ & 2016 & 2018 & En proceso & - & - & En proceso & No & No \\
\hline
\end{tabular}


Cuadro 2. Número de personas y hogares donde se aplicaron las herramientas metodológicas en las regiones de San Martín y Ucayali

\begin{tabular}{|c|c|c|c|c|c|c|c|c|c|c|c|}
\hline \multirow[t]{2}{*}{ Región } & \multirow{2}{*}{$\begin{array}{c}\mathrm{N}^{\circ} \text { de hogares en } \\
\text { las comunidades } \\
\text { (total) }\end{array}$} & \multirow[t]{2}{*}{$\begin{array}{l}\mathrm{N}^{\circ} \text { de hogares } \\
\text { seleccionados }\end{array}$} & \multicolumn{3}{|c|}{$\begin{array}{l}\text { Informantes } \\
\text { clave }\end{array}$} & \multicolumn{3}{|c|}{$\begin{array}{l}\text { Grupos Focales } \\
\text { (participantes) }\end{array}$} & \multicolumn{3}{|c|}{$\begin{array}{l}\text { Encuestas de } \\
\text { hogares }\end{array}$} \\
\hline & & & $\mathrm{H}$ & $M$ & Total & $\mathrm{H}$ & $M$ & Total & $\mathrm{H}$ & $M$ & Total \\
\hline Ucayali & 285 & 96 & 18 & 22 & 40 & 62 & 77 & 139 & 90 & 86 & 176 \\
\hline San Martín & 265 & 85 & 15 & 7 & 22 & 79 & 66 & 145 & 81 & 81 & 162 \\
\hline Total & 550 & 181 & 33 & 29 & 62 & 141 & 143 & 284 & 171 & 167 & 338 \\
\hline
\end{tabular}

medio de talleres organizados en cada comunidad participante y con los gobiernos regionales. Para cada una de las 12 comunidades se preparó un resumen de los resultados, que fue presentado en un taller comunal, y se realizaron una o dos capacitaciones de alrededor de una hora sobre el procedimiento de titulación y sobre manejo forestal comunitario (según fuera solicitado). Además, se entregaron copias de los informes comunales correspondientes.

En las capitales regionales se realizaron talleres de difusión para funcionarios del gobierno regional, representantes del sector indígena, de proyectos de desarrollo y la sociedad civil con el fin de informar sobre los talleres comunales y presentar una síntesis de los resultados de la investigación en la región. Todas las actividades se desarrollaron entre el 9 y el 26 de abril de 2019. En San Martín participaron 117 personas (94 hombres y 23 mujeres) en las seis comunidades, y 18 personas (16 hombres y 2 mujeres) en el taller regional de Moyobamba. En Ucayali participaron 116 personas (63 hombres y 53 mujeres) en las seis comunidades, y 25 personas en los talleres regionales en Atalaya y Pucallpa (20 hombres y 5 mujeres). Las personas e instituciones que participaron en esta etapa recibieron talleres y documentos; y manfiestaron luego que estos materiales les servirán como herramientas para tomar mejores decisiones. 


\section{Síntesis de los resultados}

Esta sección presenta los resultados del análisis en tres partes. La primera parte aborda la formalización y la seguridad e inseguridad de la tenencia de tierras, la segunda resume los resultados de las percepciones de las comunidades sobre el impacto del proceso de titulación en los medios de vida y en la condición de los bosques, y la tercera presenta algunas observaciones sobre el uso y la clasificación de los territorios.

\subsection{La formalización y la seguridad de la tenencia de tierras}

En general, la percepción de las personas entrevistadas acerca del proceso de formalización y sus resultados fue positiva y optimista. El reconocimiento de los derechos de propiedad es una prioridad para los pobladores de estas comunidades. Por esa razón, cuando hay avances en el reconocimiento, en el saneamiento físico y legal de sus tierras a través del proceso de titulación, las comunidades lo reciben positivamente y mejoran su percepción sobre la seguridad de sus derechos a la tierra. Sin embargo, aún existen algunos desafíos que impiden el desarrollo adecuado y la culminación del proceso. En esta sección se presenta un resumen de las percepciones del proceso de titulación y sus resultados, así como de los cambios en la seguridad. Más adelante se incluye una discusión sobre los factores que afectan la seguridad o inseguridad de la propiedad comunal desde el punto de vista de los hombres y mujeres entrevistados en las comunidades.

\subsubsection{Percepciones del proceso de formalización}

En ambas regiones, la participación de las comunidades en los procesos de formalización se realizó por medio de las juntas directivas, debido a que sus integrantes tenían más información y conocimiento sobre los pasos y actividades asociados con la formalización de los derechos de propiedad. Los informantes clave en todas las comunidades explicaron que las juntas directivas colaboraron estrechamente con las federaciones regionales para hacer el seguimiento de los procesos de titulación. Luego que las comunidades fueron reconocidas por el gobierno, estas juntas presentaron las solicitudes para iniciar el proceso de titulación, lideraron las comunicaciones y negociaciones con el gobierno regional durante todo el proceso, y se hicieron cargo de obtener información en campo y de los procedimientos en las instituciones.

En todas las comunidades en San Martín, los informantes mencionaron que sus federaciones se encargan del seguimiento del proceso de titulación e informan a los presidentes comunales. En Ucayali, la junta directiva comunal tiene mayor protagonismo y la federación presta apoyo durante el desarrollo del proceso. Según los informantes clave, el gobierno regional es el encargado de implementar el proceso y de la demarcación/georreferenciación del territorio, con más énfasis en San Martín que en Ucayali. Además, resaltaron que la comunidad acompaña a los actores gubernamentales durante la demarcación y georreferenciación del territorio, pero no mencionaron su participación durante el estudio de suelos (un paso en la clasificación de la tierra). Generalmente, los informantes locales tenían menos conocimiento sobre las otras etapas que se realizan fuera de la comunidad, como la aprobación del plano territorial y la emisión de títulos, aunque algunos líderes sabían más detalles del proceso.

Es importante señalar que existe un desbalance notable en la participación, en términos de género. Cuando se preguntó a los informantes clave y grupos focales sobre la participación de hombres y mujeres en el proceso de titulación, la respuesta general fue que todos los miembros 
adultos de las comunidades, hombres y mujeres, tienen derecho de participar con voz y voto. Sin embargo, en la práctica, la realidad es distinta. En San Martín, las mujeres de dos grupos focales sentían que estaban excluidas de las reuniones y en los otros cuatro grupos afirmaron que tenían pocas opciones de participar, debido a las tareas domésticas y al cuidado de sus hijos. De esa forma, las mujeres percibieron tener poca o nula participación y que sus opiniones no fueron consideradas en la toma de decisiones de la comunidad. De manera similar, en Ucayali, las mujeres de un grupo focal explicaron que no se sentían seguras de participar en las discusiones porque no tenían suficiente conocimiento del tema. En los demás grupos focales, las mujeres indicaron que su participación en las reuniones donde se toman decisiones era menor que la de los hombres, principalmente a causa de las responsabilidades del hogar. En contraste, en los grupos focales masculinos de Ucayali, los hombres reconocieron y señalaron tener mayor participación en las actividades y reuniones donde se toman decisiones y contar con mayor conocimiento sobre los acontecimientos en la comunidad. Sin embargo, en estos temas, las entrevistas fueron fuertemente influenciadas por las opiniones de los líderes.

Las actividades y reuniones relacionadas con el proceso de titulación eran eventos que generaban mucho interés entre los pobladores, sin embargo, se pueden comparar con los patrones de participación en reuniones comunales cotidianas para observar realmente cómo funcionaba la toma de decisiones comunales. En la encuesta de hogares se preguntó si habían participado en asambleas sobre reglas para el uso del bosque. En la muestra total, las respuestas eran que $37 \%$ de los hombres había participado, en comparación con solo $17 \%$ de las mujeres. En San Martín, el 52\% de los hombres y solo $16 \%$ de las mujeres participaron en reuniones para tomar decisiones. En Ucayali, 22\% de los hombres participó en las reuniones de toma de decisiones sobre el uso del bosque y solo $18 \%$ de las mujeres encuestadas.

A pesar de su bajo nivel de participación, los hombres y las mujeres dijeron estar satisfechos con el proceso. Durante los grupos focales, después de discutir los pasos para la formalización del territorio, se pidió a los participantes calificar su nivel de satisfacción con el proceso de titulación de sus tierras (de manera anónima) con las opciones "satisfecho", "indiferente" o "insatisfecho". El 87\% señaló estar satisfecho con el proceso hasta ese momento, con poca variación entre San Martín (91\%) y Ucayali (83\%). Al desagregar la muestra, en Ucayali el subgrupo con menor grado de satisfacción estaba compuesto por hombres $(82 \%)$ y participantes de la comunidad no titulada (76\%), aunque en ambos grupos el nivel de satisfacción es alto. En San Martín no existe una diferencia marcada en términos de género o situación de la titulación.

\subsubsection{Percepciones sobre la seguridad de los derechos de propiedad}

En la encuesta de hogares se preguntó a hombres y mujeres cómo había cambiado la seguridad del territorio con el proceso de titulación. Las preguntas específicas comparaban la seguridad a partir del proceso de titulación y la situación actual. También se preguntó sobre la percepción de comuneros y comuneras acerca de los cambios en la seguridad en los últimos 5 años. Por último, y para analizar las percepciones de la situación actual de la seguridad de la tierra en las comunidades, se preguntó acerca de los factores que generan seguridad o inseguridad y cuál era la ocurrencia de conflictos en la población.

Los resultados de la encuesta de hogares mostraron una fuerte percepción de seguridad como resultado del proceso de titulación. Se preguntó: “¿Desde que su comunidad se tituló (demarcó), siente que sus derechos y acceso a la tierra y los bosques son fuertes y seguros?”. El 80\% de los hombres y mujeres encuestados estuvo de acuerdo con el enunciado (figura 3), sin diferencias significativas entre San Martín y Ucayali. Sin embargo, un mayor porcentaje de hombres (82\%) estaba de acuerdo en comparación con las mujeres $(78 \%)$, con una diferencia significativa $(\mathrm{p}=0.005)$. También, un mayor porcentaje de encuestados de comunidades tituladas (85\%) estaba de acuerdo con esta afirmación, en comparación con los de las comunidades no tituladas (74\%), con diferencia significativa $(\mathrm{p}=0.009)^{2}$. En Ucayali, el porcentaje de personas que estaba de acuerdo variaba entre

2 Según el Test de Chi cuadrado, con un valor de $\mathrm{p}$ de 0.005 y un nivel de confianza al $95 \%$, se puede afirmar que existe una asociación estadísticamente significativa entre el género del consultado y su percepción sobre el impacto del proceso de titulación en la seguridad. 


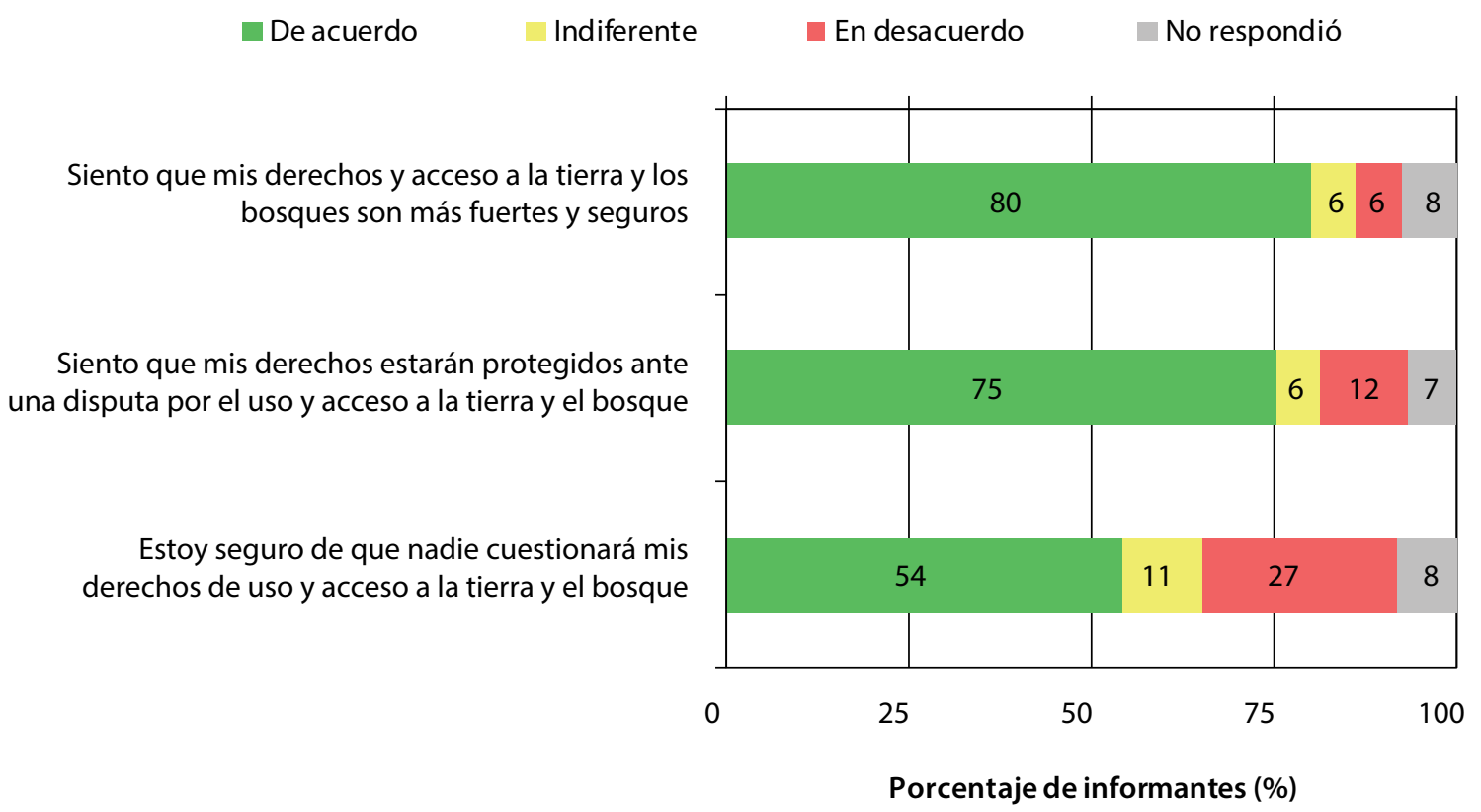

Figura 3. Cambios en la seguridad desde la titulación o demarcación

las comunidades tituladas (80\%) y la comunidad no titulada (48\%), con una diferencia significativa $(\mathrm{p}=0.0003)$.

En general, los resultados en las regiones Ucayali y San Martín son similares a los obtenidos en el estudio GCS-Tenure en Loreto y Madre de Dios. En este último, el $81 \%$ del total de informantes estuvo de acuerdo en que la seguridad mejoró a partir de la titulación o demarcación, sin diferencias significativas entre Madre de Dios (82\%) y Loreto (80\%) (Cruz-Burga et al. 2017).

Entre los encuestados, también había la percepción de que los derechos otorgados están protegidos en caso de conflictos por el acceso a los recursos. En la encuesta de hogares se preguntó: “ ¿Desde que su comunidad se tituló (o fue demarcada), siente que sus derechos están protegidos ante una disputa por el uso y acceso a la tierra?”. El $75 \%$ estuvo de acuerdo, sin diferencias significativas entre San Martín (80\%) y Ucayali (70\%). Las familias señalaron que la titulación (pos demarcación), reconoce formalmente sus derechos de acceso a la tierra, por ello están legalmente protegidas ante una disputa.

Si bien los comuneros y comuneras consultados se sienten seguros y confían en que sus derechos están protegidos, hay preocupación de que personas o empresas externas puedan quitarles estos derechos en el futuro. En la encuesta de hogares se preguntó: “¿Desde que su comunidad se tituló (demarcó), está seguro(a) que nadie cuestionará sus derechos de acceso y uso de la tierra y los bosques?” En toda la muestra, $54 \%$ de los consultados está de acuerdo, con diferencias entre San Martín (64\%) y Ucayali (45\%). En ambas regiones, los casos de invasión y extracción ilegal de recursos son recurrentes, tanto en las comunidades tituladas como en las demarcadas. Además, en Ucayali un porcentaje mayor (42\%) en comparación con San Martín (11\%), está en desacuerdo con la afirmación. En Ucayali, algunas comunidades tienen conflictos por la superposición de derechos sobre la tierra con Bosques de Producción Permanente (Tzinquiato y Capajeriato) y por tierras en posesión de foráneos dentro del territorio comunal (Centro Chocote y Aerija).

Con el objetivo de identificar los cambios en las percepciones sobre la seguridad se preguntó: ¿En su opinión, la situación de la seguridad de tenencia de la tierra y el bosque ha cambiado durante los últimos 5 ańos en esta comunidad? El $82 \%$ respondió que la seguridad 'había mejorado' (42\%) o 'sigue siendo la misma' (40\%). Solo el 9\% manifestó que la seguridad 'había empeorado'. Los subgrupos con una mayor percepción de mejora en la seguridad fueron las comunidades no tituladas 
(56\%), en comparación con las tituladas (38\%), siendo esta diferencia estadísticamente significativa $(\mathrm{p}=0.003)$. Estas percepciones están influenciadas por el hecho de que las comunidades no tituladas han sido recientemente demarcadas y algunas de las comunidades tituladas fueron georreferenciadas, mientras que otras no tuvieron avances en el proceso de titulación (actualización del título).

Existen similitudes entre este estudio y los casos analizados en las regiones de Madre de Dios y Loreto por el Proyecto GCS-Tenure sobre la percepción de mejora en la seguridad (48\% de los y las encuestados). Sin embargo, hay una diferencia marcada con relación a la idea de que la seguridad empeoró en los últimos ańos. En Loreto, los resultados son similares a los de este estudio (11\%), pero en Madre de Dios, un porcentaje mucho más alto señaló que la seguridad empeoró $(27 \%)$. Esta diferencia entre Loreto y Madre de Dios es significativa $(\mathrm{p}=0,001)$ (Cruz-Burga et al. 2017).

\subsubsection{Percepciones de los factores de la seguridad de la tierra}

La investigación indagó acerca de los factores que intervienen en la seguridad e inseguridad de la tenencia de tierras entre los pobladores de las comunidades seleccionadas. En las entrevistas con informantes clave y con grupos focales, las respuestas más comunes sobre los factores de seguridad fueron: el reconocimiento de los derechos de propiedad a través del proceso de titulación, la mejor articulación y colaboración entre organizaciones indígenas regionales y locales, y la ocupación y defensa colectiva de los territorios.

Según todos los informantes clave y los participantes en grupos focales, el título es uno de los principales factores de seguridad de tenencia. Sin embargo, el solo hecho de iniciar el proceso de formalización les da seguridad, debido a que desde ese momento el Estado comienza a reconocer sus derechos sobre la tierra. Esta situación también se ha dado en otros procesos de formalización, documentados en otras zonas (Cronkleton y Larson 2015). El reconocimiento es más que simbólico, debido a que en la primera etapa de demarcación se realiza el establecimiento legal de los límites, que sirven de referencia para la defensa de los derechos territoriales. Para demarcar los límites, el Estado solicita acuerdos de colindancia con comunidades vecinas y otros actores aledaños, los que se formalizan en 'Actas de Colindancia'. Es mediante estos acuerdos, avalados por el Estado, que las comunidades obtienen el reconocimiento de sus derechos territoriales.

Para los consultados, la seguridad no es resultado de las acciones del Estado únicamente. Los hombres y mujeres que fueron informantes clave y participaron en los grupos focales mencionaron que el proceso de titulación mejoró gracias a la articulación y colaboración activa entre las juntas directivas comunales y las federaciones indígenas. Esto fue enfatizado por ocho informantes clave y cinco grupos focales de tres comunidades (Capajeriato, Inkare y Tzinquiato). La relación entre la comunidad y su federación es importante para hacer seguimiento del proceso de titulación y asegurar la culminación y consolidación de sus objetivos. Además, este tipo de acción colectiva es importante para la protección de los territorios frente a las amenazas más frecuentes (como invasiones o extracción ilegal de recursos) y también para la resolución de conflictos.

Otro factor de seguridad citado es la ocupación física de las tierras y la defensa activa del territorio. Los consultados señalaron que la distribución de parcelas agrícolas a los comuneros representaba no solamente una opción para sus medios de vida, sino también una defensa segmentada del territorio, al ser este ocupado y usado. Además, en algunas comunidades de San Martín y Ucayali, la protección que ofrece la propia comunidad ante amenazas externas como invasiones y extracción ilegal de recursos (por medio de brigadas o comités de vigilancia comunal), es también un factor de seguridad. Por ejemplo, en la comunidad demarcada de Santa Rosa de Alto Chambira, en San Martín, hubo intentos de invasión luego de la demarcación, pero fueron advertidos por el comité de vigilancia que identificó trochas de acceso hechas por foráneos y tomó las medidas pertinentes. En la comunidad de Nueva Esperanza, en Ucayali, cuando los comuneros se dirigen al bosque para cazar también monitorean los límites del territorio y si algo extraño sucede, informan inmediatamente al jefe comunal.

El estudio también indagó sobre los factores de inseguridad. Aunque hubo satisfacción con los avances en el proceso de titulación y existía una percepción general de seguridad a nivel individual, el tema de la inseguridad de los derechos de propiedad ocupó un lugar destacado en las 
discusiones y entrevistas con informantes en ambas regiones. En los grupos focales, las respuestas más comunes sobre los factores de inseguridad eran: las amenazas de invasión de los territorios y la extracción ilegal de recursos naturales por parte de terceros, la débil respuesta del Estado para mediar en conflictos exacerbados durante el proceso de titulación y la inestabilidad y falta de exclusividad de los derechos otorgados.

Una de las principales preocupaciones estaba relacionada con los problemas derivados de la invasión de tierras y la extracción ilegal de recursos por parte de terceros, conflictos históricamente comunes. Los pobladores entrevistados en Ucayali comentaron sobre los problemas surgidos a raíz de la invasión de sus territorios comunales por parte de colonos que llegan de diferentes partes del país en busca de tierras. Por ejemplo, en las CCNN Chirikyacu y Charapillo de San Martín, dos informantes clave mencionaron que los líderes permiten la transferencia de los derechos sobre el área agrícola a personas externas, lo que es un factor de inseguridad. Además, la extracción ilegal de recursos fue identificada como la principal amenaza, después de las invasiones, en cinco de las seis comunidades en San Martín (según 8 de 12 grupos focales y 10 de los 22 informantes clave). En las comunidades de Aerija, Tzinquiato e Inkare, en Ucayali, la solicitud de ampliación de sus territorios muestra que los pobladores consideran que estas áreas aseguran recursos naturales importantes para sus medios de vida y para las generaciones futuras (según 15 de los 20 informantes clave). En un inicio, las áreas identificadas para las ampliaciones no estaban consideradas dentro de los límites de las comunidades y tienen problemas de explotación por terceros. También en las comunidades de Nueva Esperanza, Tzinquiato e Inkare, 11 de 21 informantes clave creen que, aunque se les otorgue un título totalmente saneado, persistirán los casos de extracción ilegal de recursos.

En la mayoría de las comunidades, los conflictos relacionados con la tierra o con el bosque predominaban en las conversaciones de los grupos focales. Sin embargo, en la encuesta de hogares, solo 19\% de los pobladores afirmó haber estado involucrado en algún conflicto por tierra durante el último año. Veintisiete por ciento de las personas consultadas en Ucayali mencionó la existencia de conflictos, un porcentaje mayor que en San Martín (10\%). En las comunidades no tituladas el porcentaje de conflictos $(21 \%)$ fue más alto que en las comunidades tituladas (18\%), aunque las diferencias no fueron estadísticamente significativas. En Ucayali, los informantes masculinos (33\%) mencionaron más conflictos, así como los de la comunidad no titulada (43\%), pero las diferencias tampoco eran significativas. En las comunidades incluidas en el GCS-Tenure de Madre de Dios y Loreto, el mismo porcentaje de pobladores (19\%) mencionó haber tenido un conflicto durante el último año, con una proporción mayor en Madre de Dios (30\%) que en Loreto (11\%) (Cruz-Burga et al. 2017).

A pesar de que, en general, los consultados tenían una percepción positiva del proceso de titulación, también expresaron algunas críticas. En cinco comunidades de San Martín, 20 de los 22 informantes clave y 10 de los 12 grupos focales aseguraron que algunos conflictos con terceros se agravaron durante las actividades de demarcación (como parte del proceso de titulación), es decir, cuando los límites estaban siendo definidos. Por ejemplo, en la comunidad de Chirikyacu, durante el proceso de actualización del título (georreferenciación e inscripción en registros públicos) el Estado no reconoció los acuerdos de colindancia establecidos anteriormente (según dos informantes clave y el grupo focal masculino). Estas discrepancias han hecho que las comunidades cedan tierras a actores vecinos, pese a que años antes ya habían establecido los límites, con la finalidad de culminar la actualización de sus títulos. Este fue el caso en dos comunidades tituladas (Chirikyacu y Charapillo). Estos problemas se originan por la presión constante de actores colindantes sobre los territorios comunales y, según su percepción, por el limitado resguardo y papel desempeñado por el Estado en los conflictos. En Ucayali, tres de cinco comunidades tituladas no lograron completar el proceso de saneamiento. En las cinco comunidades tituladas, y desde el reconocimiento de sus derechos hasta la actualidad, los conflictos generados por la invasión de colonos y pobladores de las comunidades vecinas continúan. Existen aún más conflictos por territorios en la comunidad de Centro Chocote, que recientemente ha iniciado los trámites para su titulación.

La falta de mecanismos que permitan la resolución de los conflictos generados durante el proceso de titulación es una deficiencia señalada por cuatro 
de 12 informantes clave y por la mitad de los grupos focales de dos comunidades (Charapillo y Chirikyacu) de San Martín. En estas dos comunidades, tituladas en 1997 y 1998, algunas familias indígenas ajenas a la comunidad fueron incluidas bajo la condición de moradores (sin ser miembros plenos de la comunidad) y se les dieron derechos sobre un área limitada y determinada por la comunidad. Sin embargo, en la actualidad, estas familias están extendiendo su uso de la tierra y generando conflictos. En estas comunidades, la población percibe que no existen mecanismos que permitan solucionar este tipo de amenazas.

Otro factor de inseguridad mencionado en ambas regiones, es la percepción de que los derechos sobre la tierra no son exclusivos de la comunidad y que el Estado podría reconocer derechos a terceros, sobrepuestos con sus territorios. En Ucayali, algunas comunidades se sienten amenazadas por la superposición con los Bosques de Producción Permanente (BPP), con el riesgo de que en el futuro el Estado otorgue concesiones forestales dentro de los territorios comunales. En San Martín, la comunidad de Juliampampa se ubica dentro del Área de Conservación Regional (ACR) Cordillera Escalera, situación que implica severas restricciones para el aprovechamiento de los recursos de su territorio. Por último, en varios grupos focales en San Martín (Tornillo, Chirikyacu y Juliampampa) y Ucayali (Aerija y Nueva Esperanza), los participantes reconocieron que los derechos sobre el subsuelo pertenecen al Estado $\mathrm{y}$ esto les representa un riesgo a futuro debido al probable otorgamiento de permisos de extracción a empresas petroleras, sin consulta previa. La idea de que los derechos sobre el territorio no son exclusivos de la comunidad es consecuencia del desconocimiento de los resultados del proceso de titulación (clasificación de tierras y cesión en uso) $\mathrm{y}$ otros mecanismos que permiten adquirir o ceder derechos (acuerdos con Âreas de Conservación Regional y permisos forestales). En relación a los contratos de cesión en uso, designados para las tierras forestales del área demarcada, ninguna de las comunidades tituladas del estudio han recibido estos contratos, pese a que forma parte del marco normativo de la titulación. Esta situación genera incertidumbre sobre los derechos adquiridos o cedidos y crea la percepción de que los derechos podrían ser revocados en cualquier momento.

Al comparar los resultados de San Martín y Ucayali con la información obtenida en las regiones de
Madre de Dios y Loreto, se encuentran similitudes en cuanto a los factores de inseguridad. Los principales factores de inseguridad en estas regiones se refieren al saneamiento inconcluso de los territorios, la falta de capacidad del Estado para ejercer y defender los derechos (Madre de Dios), y la competencia con la inversión privada (Loreto), por la presencia de compañías petroleras y madereras que amenazan la seguridad de los territorios indígenas. Un caso similar ocurre en Ucayali.

\subsection{Medios de vida}

Para muchos pueblos indígenas, la seguridad de tenencia va más allá del proceso de reconocimiento y titulación. Por ejemplo, en los talleres regionales del estudio de tenencia anterior en Madre de Dios y Loreto, los actores vincularon aspectos económicos, sociales y políticos al ejercicio del derecho, más allá de su formalización (Zamora y Monterroso, 2017). En reuniones con líderes indígenas, varios enfatizaron que el título es solo un paso en la búsqueda de mejoras en los medios de vida. Una comparación de las respuestas sobre la satisfacción con los derechos de tenencia en tres países, mostró mucha preocupación por el tema de los medios de vida (Larson et al. 2019). En algunos casos, la formalización puede introducir nuevas reglas y restricciones sobre los derechos de acceso a ciertos recursos (Cruz et al. 2018). Por esto, es importante discutir el tema.

En la encuesta de hogares, se recolectó información sobre los medios de vida de las familias, según la opinión de las jefas y los jefes del hogar. Esto significa que se tienen dos percepciones sobre los medios de vida de la familia por cada hogar (fuentes de ingreso, sistemas productivos y uso de recursos). Sin embargo, para el análisis de las variables sobre la producción familiar y los medios de vida del hogar, es necesario procesar los resultados de un solo grupo, hombres o mujeres, para evitar la replicación de datos. Al analizar la información de ambos, se observó que no existen diferencias significativas en los promedios de las variables referidas a superficies de cultivo o distribución de los usos de la tierra en el área de uso familiar. Por lo tanto, la información de los hombres y de las mujeres es representativa del hogar. No obstante, debido a que la muestra de hombres entrevistados es mayor y sus respuestas fueron más completas y detalladas, se consideró la 
información proporcionada por estos informantes masculinos. Para las preguntas sobre percepciones y opiniones, se siguió usando la muestra total.

\subsubsection{Fuentes de ingresos}

Para la mayoría de las familias encuestadas, la agricultura es el eje de la economía del hogar. Se pidió a los consultados que identifiquen su fuente principal de ingresos económicos por medio de una pregunta abierta (sin respuestas predefinidas), con énfasis en los ingresos monetarios. Los resultados muestran que, además de la agricultura, existen pocas fuentes de ingresos en las comunidades seleccionadas. En los hogares entrevistados, la agricultura es la principal fuente de ingresos para $70 \%$ de los hogares (119 de 170 hogares) y esta situación es común en ambas regiones. Los encuestados usaron una definición amplia de agricultura, que incluía cultivos anuales (principalmente maíz), semiperennes (como yuca y plátano) y otros productos de sistemas agroforestales. También, para algunos encuestados, la agricultura incluía cultivos perennes y agroforestales, como cacao o café. La segunda fuente de ingresos mencionada por $8 \%$ de los encuestados (14 de 170 hogares) fue la crianza de animales, otro aspecto del sistema agropecuario. Esta se refiere a la crianza de aves (5\%), la ganadería $(2 \%)$ y la crianza de cerdos $(1 \%)$.

Existen pocas actividades no agropecuarias que son fuentes principales de ingresos. Solo 10 familias, o sea $6 \%$ de los encuestados, dieron información sobre otras actividades económicas como empleos (2\%), negocios propios (2\%) y trabajo independiente (1\%). En San Martín, debido a la facilidad de acceso a ciudades cercanas (por la carretera), las actividades no agropecuarias son la fuente principal de ingresos para el $12 \%$ de las familias. Sin embargo, 15 de los 170 informantes (9\%) reportaron que no tenían una fuente de ingresos monetarios definida. En otras palabras, subsisten gracias a la agricultura o la extracción de recursos naturales, tienen ingresos eventuales por empleos temporales o por la venta de algún producto, pero no tienen una actividad específica para generar ingresos.

Actividades como la caza, la pesca y la extracción de madera (que son importantes para la subsistencia), no son fuentes principales de ingresos. Solo una familia (1\%) mencionó la pesca y otra familia refirió la venta de madera como fuentes principales de sus ingresos. Por último, un 5\% de hogares no respondió esta pregunta. Cuando se preguntó sobre artesanía específicamente, solo la mayoría de mujeres de la comunidad de Chirikyacu, en San Martín, afirmó que esta que generaba ingresos, pero menores a los de las demás actividades.

Para tener otro indicador del estatus económico, se pidió a los informantes que estimen su ingreso monetario mensual promedio. Esta información fue proporcionada por 85 de los 170 hogares (50\%). Así, el valor promedio del ingreso familiar fue de 218 soles mensuales (aproximadamente USD 66), cantidad que resulta reducida para cubrir la educación de los hijos, medicinas, productos comerciales, etc. Los montos variaban entre 0 a 1250 soles (aproximadamente USD 381). De los 85 hogares que no respondieron, 15 reportaron no tener fuentes de ingresos, 6 no conocían los ingresos mensuales del hogar y 64 prefirieron no brindar esta información. Los resultados del estudio muestran que la economía de los hogares se basa principalmente en la agricultura y, por esta razón, la seguridad de tenencia de la tierra es fundamental. Además, actividades como la agricultura y la crianza de animales menores son recursos importantes para la alimentación y subsistencia de las familias. En las siguientes secciones se describirán las características del uso de los recursos del bosque, como la caza y la pesca.

\subsubsection{El uso de la tierra}

Para entender los sistemas de producción agrícola de las comunidades, se preguntó a los encuestados sobre el uso de sus tierras de forma individual/familiar y sobre las características de sus usos. A pesar de que el entorno de cada comunidad y región es diverso, se hallaron ciertas características y patrones comunes que se presentan a continuación.

Los hogares de la muestra estimaron el tamaño de las áreas de uso familiar. Si bien existe un rango amplio de superficies, el área agrícola no presenta mucha variación entre las familias de ambas regiones. El área de uso individual/ familiar tenía en promedio 2.6 ha con un rango de superficies entre 0.4 ha y 12 ha. Solo 17 de los 170 hogares $(10 \%)$ tenía superficies mayores a 5.2 ha (dos veces el promedio). 
Los encuestados describieron el uso actual de sus parcelas, según las siguientes categorías ${ }^{3}$ :

1. Cultivos anuales: cuya siembra y cosecha se realiza solo en un año (por ejemplo, maíz $y$ frejol).

2. Cultivos semiperennes: o cultivos que permanecen en las parcelas por más de un año a (por ejemplo, plátano y yuca).

3. Cultivos agroforestales: son los que combinan diferentes especies de árboles con productos agrícolas (por lo general especies maderables, cacao y café).

4. Pastizales: son áreas de pasto mantenidas para la producción de ganado vacuno.

La Figura 4 muestra la importancia relativa en términos de superficie según los diferentes tipos de uso.

El uso para 'cultivo anual' fue la categoría más común, según $62 \%$ de los encuestados (106 de 170 hogares). El promedio de la superficie de estas parcelas era de 1 ha y los cultivos anuales cubrían el 33\% del área total usada por las familias encuestadas.

El segundo uso más común fue para los cultivos semiperennes, con un porcentaje de $49 \%$ (83 hogares). Los cultivos semiperennes más comunes fueron los de plátano y yuca, muy importantes para la alimentación local. De los 64 encuestados

3 Las categorías incluyeron 'purmas', pero fueron excluidas del análisis. Las purmas son tierras en descanso para permitir la regeneración del bosque y recuperar la fertilidad, controlar las malezas y tener áreas de extracción de otros productos como leña, carne de monte y bolaina. En un principio, hubo mucha variación en los reportes sobre parcelas con purmas.

Casi una tercera parte $(29 \%)$ de la superficie total usada por los encuestados estaba conformada por purmas. Sin embargo, solamente 54 informantes (32\%) reportaron purmas en sus áreas (con una superficie típica de 2 ha y un rango de 1 a 20 ha), y solo tres reportaron superficies mayores a 10 ha. Debido a que las familias generalmente practican una agricultura de corte y quema, se puede asumir que todas producen purmas o bosques secundarios cuando dejan la tierra en descanso. Es posible que algunas personas no califiquen las purmas como áreas de uso familiar.

También se incluyó la categoría 'bosque' para ver si los encuestados incluían áreas forestales dentro de sus parcelas de uso familiar. Según los líderes comunitarios, no existen normas consuetudinarias que permitan la distribución de derechos individuales sobre los bosques, pero la inclusión de esta categoría permitió la verificación de esta regla en la práctica. De hecho, solo dos encuestados (1\%) mencionaron tener bosques en sus áreas de uso familiar y en superficies muy pequeñas.

\section{Superficie cubierta por usos de la tierra}

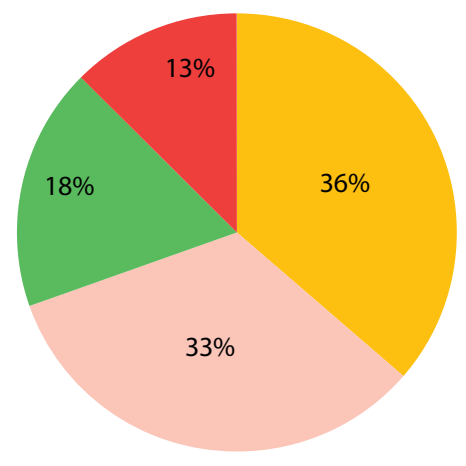

$$
\begin{aligned}
& \square \text { Cultivo semiperenne } \quad \square \text { Agroforestal } \\
& \square \text { Cultivo anual } \\
& \text { Pastizal }
\end{aligned}
$$

Figura 4. Usos de la tierra por las comunidades de San Martín y Ucayali

que no reportaron cultivos anuales, 57 reportaron cultivos semiperennes. La parcela típica de estos cultivos tenía un promedio de 2 ha, con un rango de 0.5 a 12 ha. Solamente 12 de estos consultados tenían cultivos semiperennes con más de 3 ha. El uso de estas áreas grandes era principalmente para cultivos de plátano. Las parcelas con cultivos semiperennes cubrían el 36\% del área total.

Los cultivos agroforestales fueron mencionados por el $27 \%$ de los encuestados ( 46 hogares). La superficie de las áreas agroforestales fue en promedio 2 ha, con un rango de 0.4 a 5 ha. Por lo general, estas parcelas tienen cultivos de cacao o café en combinación con especies maderables que generan sombra y con cultivos anuales en las primeras fases del sistema. Las parcelas agroforestales ocupaban el 18\% del área total usada.

Las áreas para pastizales fueron mencionadas solamente por el 11\% (19 hogares). Para ellos, la superficie típica de un pastizal era en promedio 3 ha, con un rango de 1 a 7 ha. Este uso empleaba el $13 \%$ del área total.

En general, los resultados indican que los hogares seleccionados practican una agricultura familiar de pequeña escala. Existen diferencias entre las regiones en cuanto a sistemas productivos familiares, pero no son significativas estadísticamente. En San Martín, los cultivos anuales y los pastizales son menos comunes que en Ucayali, y los cultivos semiperennes son más 
comunes. No se halló una variación relevante por pueblo indígena (varias comunidades) en los sistemas agrícolas de la muestra.

\subsubsection{El uso de los recursos del bosque}

La gran mayoría de los territorios estudiados tiene áreas forestales que ofrecen reservas importantes para los pobladores. Estos recursos forestales desempeñan un rol relevante en los medios de vida locales, especialmente para la subsistencia. En la encuesta se preguntó sobre el uso de recursos naturales a través de la caza, la pesca, la extracción de madera y de productos forestales no maderables.

\section{Caza}

La cacería es una actividad tradicional de los pueblos indígenas amazónicos que contribuye a la seguridad alimentaria de las familias y es una fuente importante de proteínas. Los resultados muestran que se trata de una actividad de subsistencia esencial $y$, aunque es importante para $68 \%$ de los hogares, es todavía más importante en Ucayali que en San Martín (Figura 5). Según los consultados, la caza es una actividad comercial solamente para 13 hogares (8\%).

Entre los hogares que cazan, 57 (49\%) lo hacen por lo menos una vez por semana, la mayoría en
Ucayali (50 u 88\%). El 62\% de los encuestados (105) declaró consumir carne de monte. Todos los cazadores en Ucayali consumen lo que cazan, con un 56\% (49) que come carne de monte cada semana.

\section{Pesca}

Es otra actividad importante que contribuye a la seguridad alimentaria de los pobladores de la Amazonía. En total, 107 de los encuestados hombres (63\%) pescan (Figura 6). Sin embargo, la pesca es una actividad más recurrente en Ucayali que en San Martín, debido al mayor acceso a ríos y quebradas. En Ucayali, 76 de 87 pobladores consultados (87\%) utilizan este recurso para alimentación. En San Martín, solo 31 encuestados (37\%) pescan. La mayoría de los hogares pesca con mucha frecuencia. Entre ellos, 78 familias (73\%) realizan actividades de pesca por lo menos una vez por semana.

En la muestra, hay más encuestados que consumen pescado que aquellos que pescan. Ciento quince de 170 consultados dijeron que consumían pescado y la mayoría (88 o $52 \%$ ) lo hace por lo menos una vez a la semana. En Ucayali, 78 familias (90\%) señalaron consumir pescado semanalmente. En cambio, en San Martín, menos familias (10 o $12 \%)$ consumen pescado por lo menos una vez a la semana.

Hogares que cazan

Total

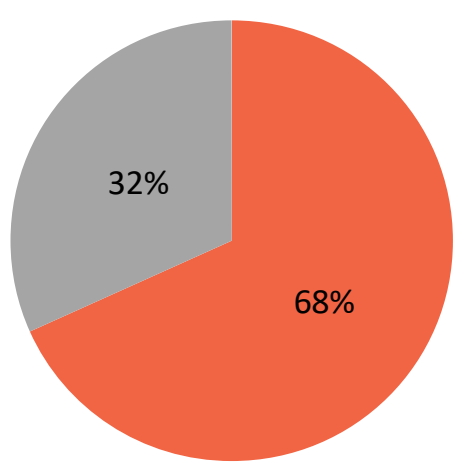

San Martín

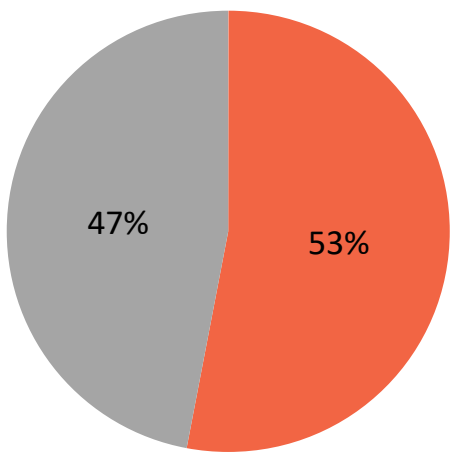

Sí $\quad$ No
Ucayali

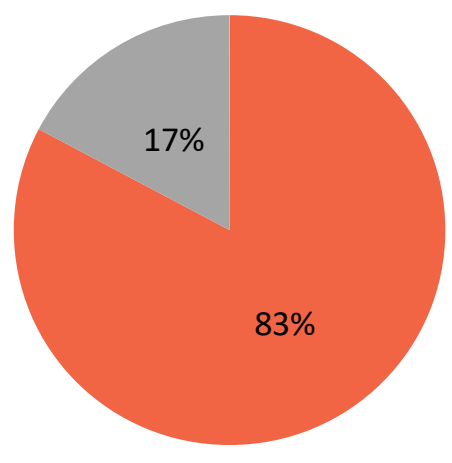

Figura 5. Porcentaje de hogares que realizan actividades de caza en San Martín y Ucayali 


\section{Hogares que pescan}
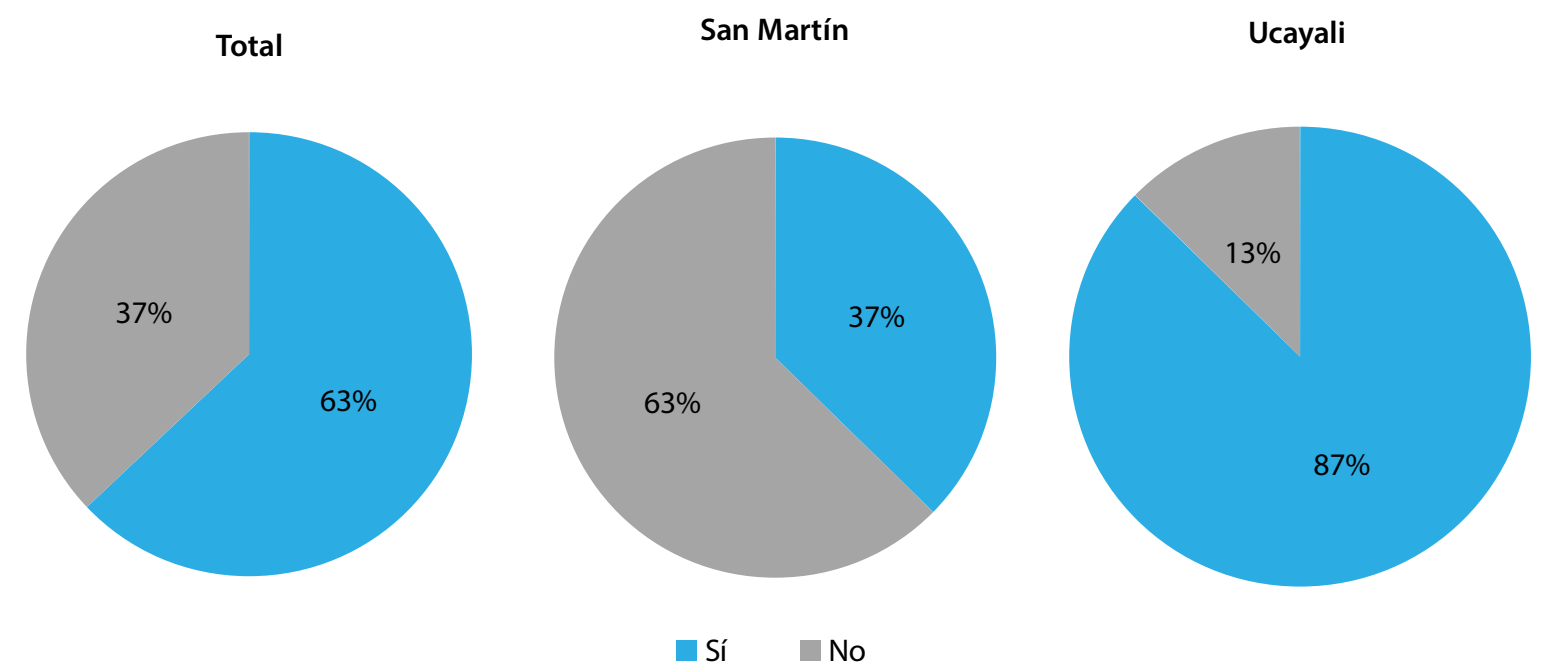

Figura 6. Porcentaje de hogares que practican la pesca en San Martín y Ucayali

Estos resultados reflejan la importancia de la pesca en los medios de vida de las familias, principalmente en Ucayali. Esta es una actividad importante para la alimentación, pero no como fuente de ingresos para los pobladores. Solo 10 hogares $(9 \%)$ venden pescado, todos en Ucayali. La pesca era fuente principal de ingresos solo para un entrevistado en Ucayali.

\section{Otros recursos del bosque}

Las comunidades amazónicas utilizan una gama amplia de productos del bosque como frutos, hojas de palmeras, plantas medicinales y madera, que son insumos importantes para los medios de vida de las familias. En la encuesta de hogares se preguntó si en el último año las familias habían recolectado algún producto del bosque, no maderable y maderable. Los resultados muestran que más de la mitad de los hogares (96 de las 170 familias o 56\%) había aprovechado algún producto no maderable en el último año (Figura 7). Esta proporción es mayor en Ucayali (55 o 63\%) que en San Martín (41 o 51\%), debido a la mayor disponibilidad de recursos naturales en la región de Atalaya.

También se preguntó sobre el aprovechamiento de recursos específicos como el fruto del aguaje (Mauritia flexuosa), las hojas de la palmera del Irapay (Lepidocarium tenue) y la corteza medicinal uña de gato (Uncaria sp.).
Treintaicuatro encuestados (20\%) informaron cosechar aguaje, la mayoría (26) de Ucayali; en San Martín, solo ocho encuestados (9\%) extraían aguaje. Un $73 \%$ de los que cosechan aguaje lo comercializan, la gran mayoría en Ucayali. La recolección de uña de gato fue mencionada durante los grupos focales, pero solo 13 encuestados $(8 \%)$ reportaron su aprovechamiento (no hubo diferencias entre las regiones). Solo 11 consultados señalaron recolectar hojas de la palmera del Irapay (6\% de la muestra), la mayoría de ellos en Ucayali. En general, a pesar de la aparente importancia de los productos no maderables en ambas regiones (Figura 7), el aprovechamiento de estos tres productos concretos no es de mucha relevancia para la economía familiar.

Además, se preguntó sobre la extracción y venta de madera (las especies mencionadas por las familias que lo hacen se detallan en el Anexo 1). Dentro de la muestra, 60 de 170 familias (35\%) dijeron haber aprovechado madera en el último año. Los encuestados de la región Ucayali aprovechan la madera en mayor proporción (37 familias o $43 \%$ ) que en San Martín (23 familias o 28\%). Sin embargo, la venta de madera durante el último año no fue mencionada por la mayoría de los hogares. Solo 15 familias (9\%) identificaron esta actividad como una fuente de ingresos. Es posible que los pobladores de algunas comunidades hayan evitado dar respuestas al respecto ya que la venta de madera, sin los permisos necesarios, es considerada ilegal por el Estado. 


\section{¿Ha recolectado algún producto no maderable este año?}

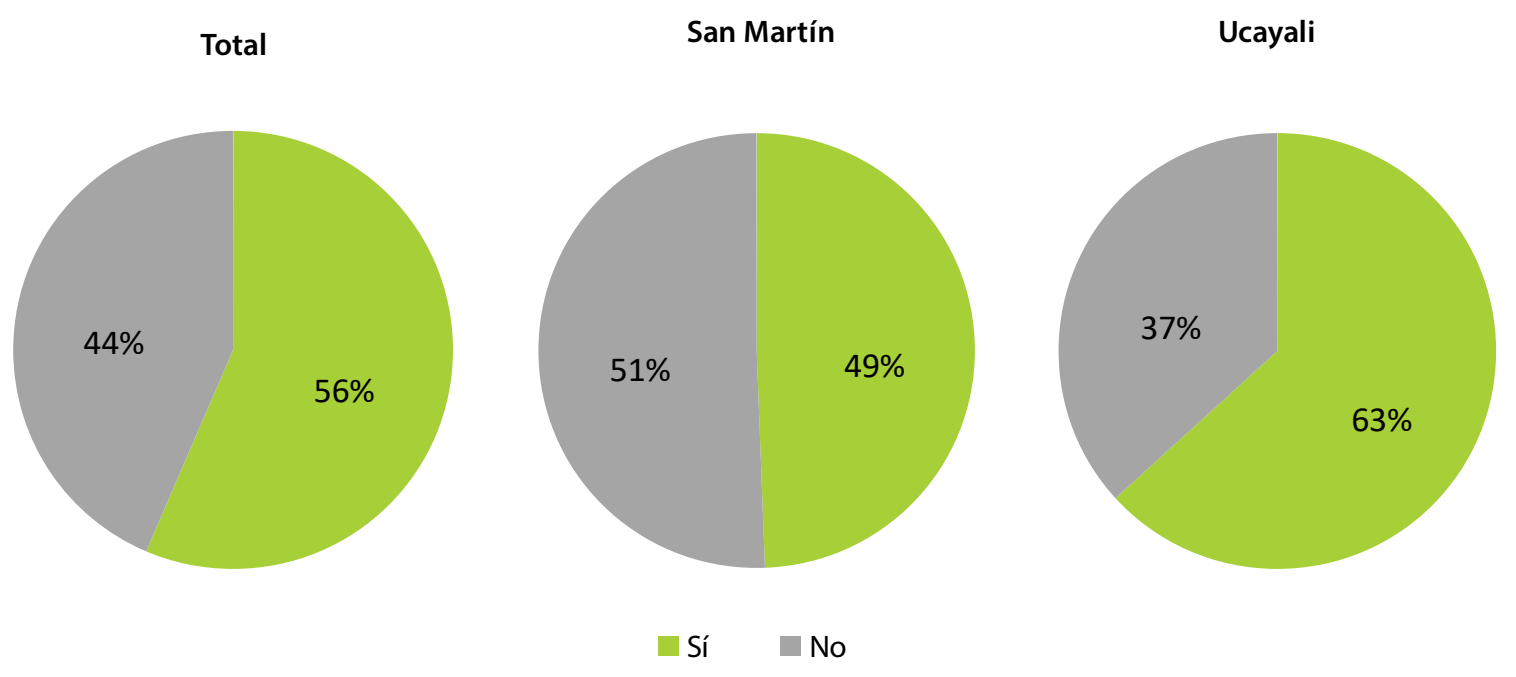

Figura 7. Utilización de productos no maderables en las regiones de San Martín y Ucayali

En Ucayali, cuatro comunidades tenían permisos para extraer madera, pero en San Martín ninguna comunidad tenía permisos vigentes hasta el 2018. En Ucayali, las experiencias con los planes de manejo varían según el tiempo que llevan en ejecución. Para Aerija -comunidad con mayor tiempo de implementación de su plan de manejoesta experiencia no fue buena, porque terminó endeudada debido a las infracciones cometidas por un maderero. En Tzinquiato, las experiencias con el plan de manejo están mejorando el aprovechamiento de los recursos. Las demás comunidades están implementando planes de manejo con miras a mejorar su calidad de vida.

Ciertos indicadores muestran que la formalización de los derechos de propiedad está dando oportunidades para el uso y manejo legal de recursos forestales. Cuatro comunidades en Ucayali (Aerija, Capajeriato, Tzinquiato e Inkare) lograron obtener permisos para extraer madera de forma legal, gracias a la titulación. Además, cinco de las 12 comunidades estudiadas (Capajeriato, Tzinquiato e Inkare en Ucayali y Chirikyacu y Chirik Sacha, en San Martín) están inscritas en el Programa Nacional de Conservación de Bosques (PNCB). Estas comunidades pueden beneficiarse del programa porque han logrado obtener sus títulos de propiedad. De la misma manera, el manejo forestal legal podría ser una opción para generar ingresos para las familias en las CCNN, en el futuro.
Estos resultados demuestran que los recursos del bosque -caza, pesca, recursos no maderables y madera- son parte tradicional e integral de los medios de vida de las familias, sobre todo para fines de subsistencia (alimentación, medicina, construcciones locales, etc.). Si bien estos productos son fundamentales para el sustento de las familias, en la mayoría de los casos, no representan una fuente de ingresos económicos importante.

\subsubsection{Percepciones sobre la situación económica del hogar}

La sección anterior presentó una descripción de las fuentes de ingresos, las actividades productivas y los usos de tierra, elementos fundamentales para los medios de vida. Esta sección describe las percepciones sobre los cambios en los medios de vida y la economía familiar. Como la información representa las opiniones individuales, se puede utilizar toda la muestra (los 338 hombres y mujeres encuestados).

En general, las percepciones optimistas sobre los cambios producidos por la titulación se reflejan en las descripciones de los medios de vida. En la muestra total, el 40\% de los encuestados mencionó que sus ingresos y medios de vida mejoraron luego de la titulación. Una mayor proporción de encuestados en Ucayali (44\%) que en San Martín (35\%) respondió así. Un grupo considerable en 
Ucayali (28\%) y uno menor en San Martín (15\%) estuvieron en desacuerdo con esta afirmación. En Ucayali, hombres y mujeres tienen posiciones contrarias. Casi la mitad de las mujeres (49\%) opina que los ingresos mejoraron mientras que el 42\% de los hombres está en desacuerdo con esta opinión. En San Martín, si bien la mayoría de hombres y mujeres no está de acuerdo ni en desacuerdo, la cantidad de mujeres que opina que la situación está peor $(22 \%)$ es mayor que la de hombres (8\%).

Para obtener más información sobre las percepciones de bienestar económico, se preguntó a los encuestados sobre su situación económica actual en comparación con la de sus vecinos y con su situación en el pasado. La pregunta fue '¿Cómo describiría su situación económica comparada con la de sus vecinos?', con las opciones de respuesta de 'buena', 'regular' y 'mala'. La mayoría de todos los encuestados (193 de los 338 o 57\%) mencionó que su situación económica es 'regular' o similar a la de sus vecinos (Figura 8). Otro grupo de 97 informantes (29\%) percibe que, en comparación con sus vecinos, su situación es 'buena'. Estas respuestas muestran una percepción de satisfacción con la situación económica del hogar por parte de los hombres y mujeres entrevistados. Solo 43 encuestados (13\%) perciben su situación como 'mala' y 5 familias (1\%) prefirieron no contestar.

En las dos regiones habían variaciones con respecto a las percepciones sobre la situación económica, aunque en ambas la mayoría opinaba que su situación era regular en comparación con la de sus vecinos. Sin embargo, también existía variación entre las percepciones negativas. En San Martín, 13 encuestados (8\%) percibían su situación como 'mala' mientras que en Ucayali 30 (17\%) clasificaron su situación económica como mala, o sea, peor que la de sus vecinos.

$\mathrm{Al}$ analizar toda la muestra, las mujeres tienen opiniones más positivas que los hombres, aunque en ambos géneros la mayoría percibe su situación económica a la par de la de sus vecinos. Esta diferencia de percepciones muestra que el impacto del proceso de titulación en los medios de vida se percibe de manera distinta entre ambos géneros. En este caso, los hombres son más críticos sobre su situación económica, debido posiblemente a percepciones diferentes sobre la situación de la agricultura. Una mayor proporción de mujeres (38\%) que de hombres (19\%) percibe que la situación económica es buena, mientras que una mayor proporción de hombres (64\%), en comparación con las mujeres (50\%), opina que su situación económica es regular. Esto es similar en ambas regiones, aunque en Ucayali las mujeres se muestran aún más positivas (Figura 9). En San Martín, el 35\% de mujeres y 20\% de hombres calificaron su economía como buena. En Ucayali, $41 \%$ de mujeres y $19 \%$ de los hombres dijeron tener una situación económica buena.

Para analizar la influencia de estos cambios (titulación, demarcación o reconocimiento) en la situación económica, se pidió que los encuestados

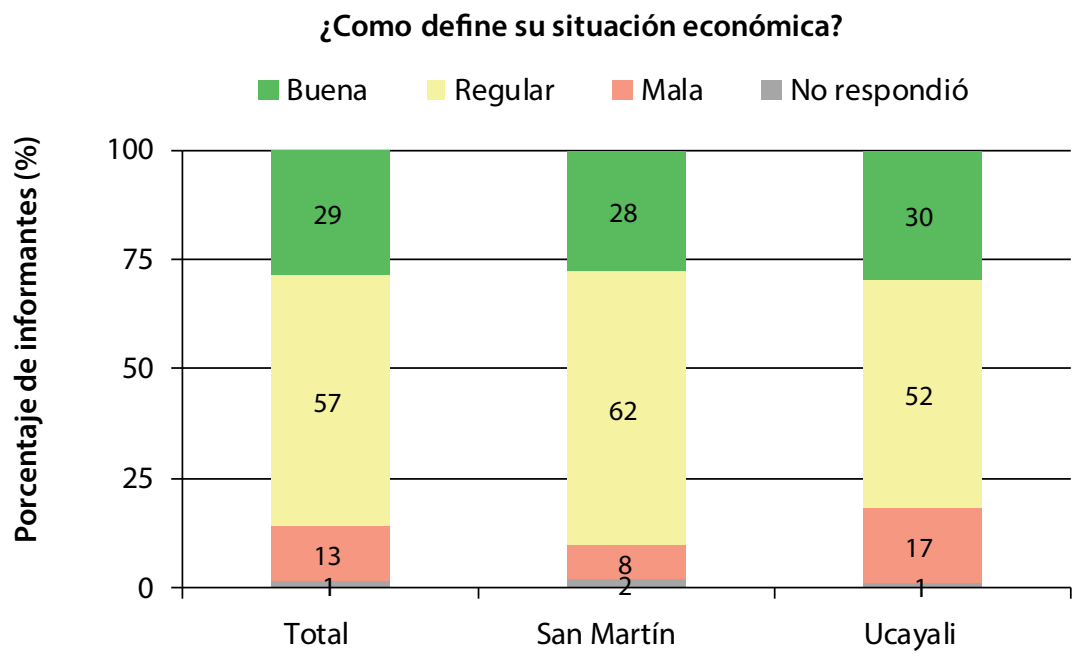

Figura 8. Situación económica de los hogares comparada con las de sus vecinos en el último año 


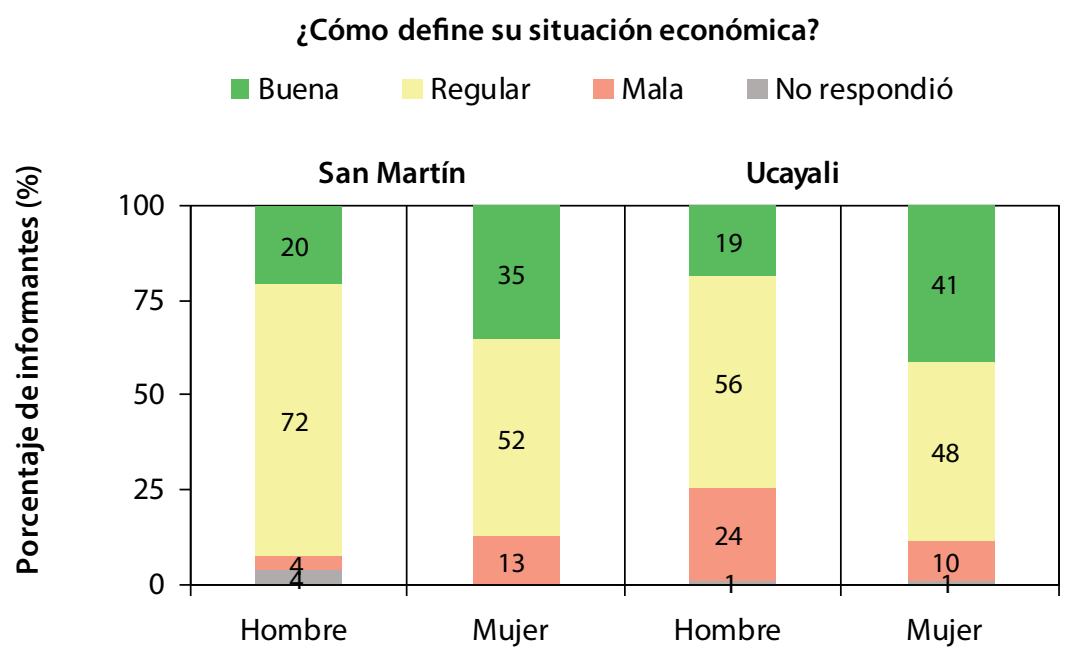

Figura 9. Situación económica de los hogares por región y género

¿Cambió su situación económica en los últimos 5 años?

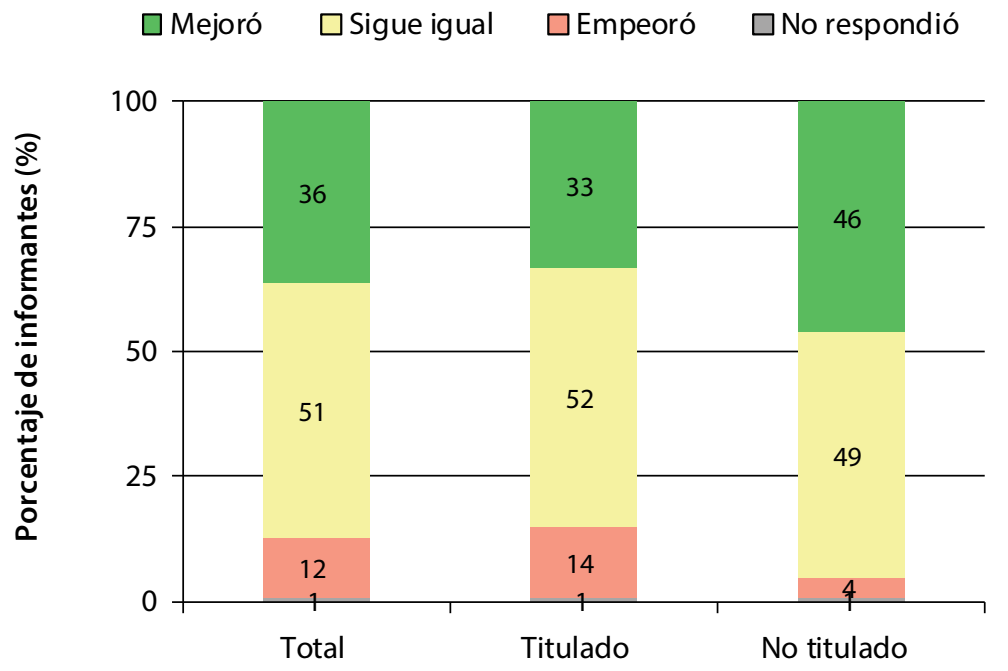

Figura 10. Situación económica en los últimos 5 años según el estado de la titulación

comparen su situación económica actual con la de hace 5 años $^{4}$. Las opciones de respuesta eran 'mejor', 'sigue igual', o 'peor'. La mayoría de hogares, 173 de 338 (51\%), contestó que la situación continúa siendo la misma, es decir, no ha percibido ningún cambio. El hecho de que la mayoría no haya percibido cambios es positivo,

4 En este estudio, todas las comunidades que están en proceso de titulación ( 4 de 12) fueron reconocidas y demarcadas en los últimos 5 ańos. Las comunidades tituladas no reportaron actividades referidas al saneamiento en este periodo. pues la mayor parte de los encuestados siente que su situación actual es regular o buena. Otro grupo (123 o 36\%) mencionó que su situación 'mejoró' económicamente. Este porcentaje es ligeramente menor en comparación con el $40 \%$ que dijo que la titulación llevó a una situación mejor. Solo 39 encuestados (12\%) percibieron que su situación 'empeoró'. No existen diferencias resaltantes entre ambas regiones en relación a estas percepciones.

Al comparar las percepciones según el estado del proceso de titulación (Figura 10), se observa que las comunidades que han logrado avances recientes 


\section{¿Cambió su situación económica en los últimos 5 años?}

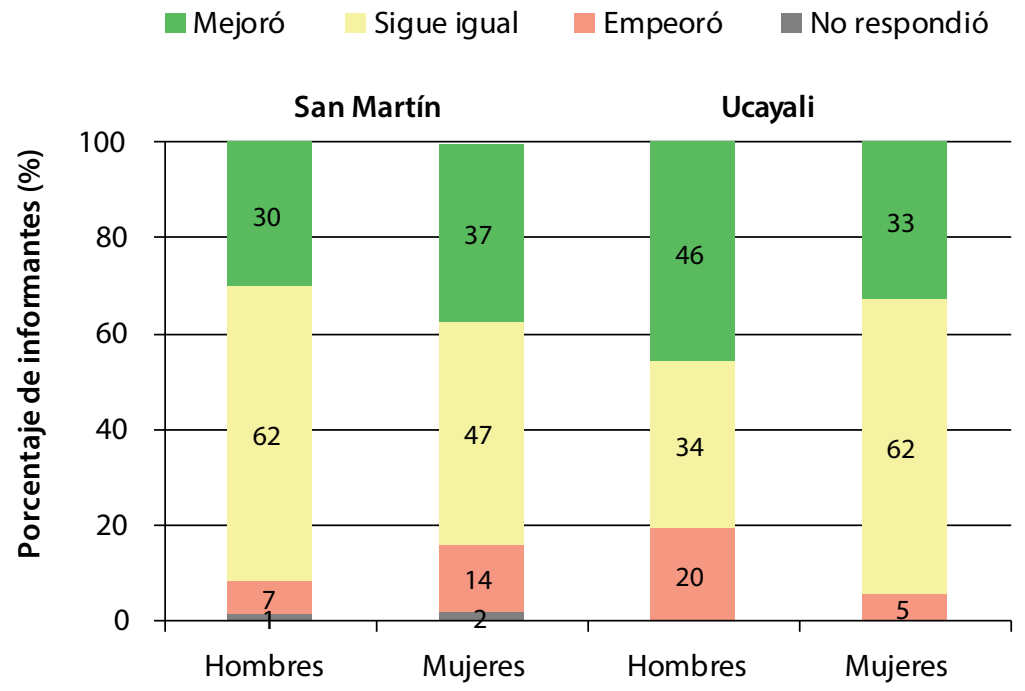

Figura 11. Situación económica por género en los últimos 5 años

tienen una percepción más optimista sobre los cambios en la situación económica. Esto puede explicarse por la disminución de la presión de actores colindantes a partir de la demarcación del territorio, lo que genera un ambiente seguro para desarrollar actividades económicas (agricultura). Además, indicaría que los avances en el proceso de titulación no solo fortalecen la seguridad de tenencia, sino que también permiten un mejor desarrollo de los medios de vida. En Santa Rosa, una comunidad shawi de San Martín en proceso de titulación, las familias afirmaron que los conflictos que fueron exacerbados al inicio del proceso disminuyeron considerablemente con la demarcación, lo que les permitió invertir más tiempo en actividades agropecuarias que en vigilancias comunales.

Cuando se analiza la muestra total en cuanto a percepción de los cambios en la economía del hogar por género, se observa que los hombres en San Martín y las mujeres en Ucayali percibieron poco cambio con más frecuencia y reportaron que la economía 'sigue igual'. Las mujeres en San Martín y los hombres en Ucayali tienen opiniones más distribuidas, tanto positivas como negativas (figura 11). La razón para estas diferencias de género y región no está clara, pero sugiere que existe una diversidad de experiencias y percepciones particulares.

\subsection{Territorio y producción}

En las comunidades seleccionadas, los hombres y mujeres que participaron en los grupos focales definieron sus territorios como un paisaje con diversos usos, que pueden variar según el género (Figura 12). Las comunidades diferenciaron las áreas en función de las prácticas que desempeñan en la actualidad: agricultura, extracción de madera y otros productos no maderables, caza y pesca. Estas actividades se realizan desde antes del proceso de reconocimiento y titulación. Sin embargo, durante la titulación, el Estado hace una zonificación del territorio, basada en un proceso llamado (desde 2018) estudio agrológico para la Clasificación de Tierras por su Capacidad de Uso Mayor (CTCUM), que distingue entre áreas aptas para agricultura y ganadería, y otras áreas con aptitud forestal o de protección. Esta zonificación es poco conocida o entendida por los pobladores de estas comunidades, aunque puede tener implicaciones importantes para sus derechos y usos de los recursos naturales.

Cuando el Estado hace la zonificación de las comunidades, solo las áreas clasificadas como aptas para la agricultura, pastos y producción permanente pueden ser tituladas como propiedad. Sobre estas áreas se entrega un título de propiedad colectiva a nombre de la comunidad. En cuanto a las áreas clasificadas como con aptitud forestal 

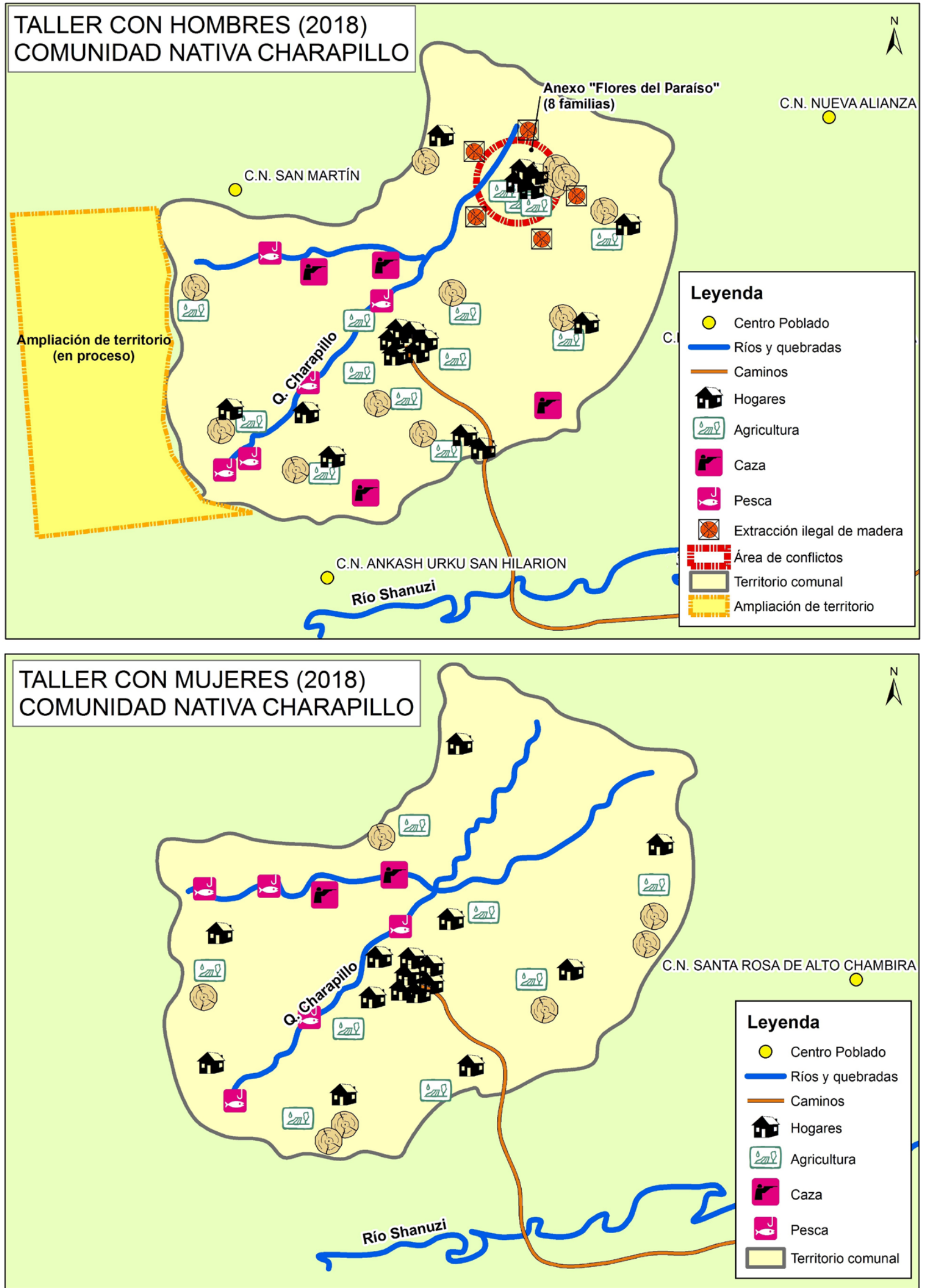

Figura 12. Mapas parlantes sobre uso de la tierra realizados por comuneros y comuneras de Charapillo, San Martín 
Cuadro 3. Zonificación de las comunidades

\begin{tabular}{|c|c|c|c|c|c|}
\hline \multirow[t]{3}{*}{ Comunidad nativa } & \multirow[t]{3}{*}{$N^{\circ}$ familias } & \multirow{3}{*}{$\begin{array}{l}\text { Área total } \\
\text { demarcada } \\
\text { (ha) }\end{array}$} & \multicolumn{3}{|c|}{ Área (\%) } \\
\hline & & & \multirow{2}{*}{$\begin{array}{l}\text { Agropecuario } \\
\text { (titulado) }\end{array}$} & \multicolumn{2}{|c|}{ Contracto de cesión en uso } \\
\hline & & & & Aptitud forestal & Protección \\
\hline \multicolumn{6}{|l|}{ Ucayali } \\
\hline Aerija & 111 & 3,092 & 67 & 33 & - \\
\hline Nueva Esperanza & 70 & 4,752 & 61 & 39 & - \\
\hline Capajeriato & 22 & 5,289 & 86 & 14 & - \\
\hline Tzinquiato & 40 & 6,717 & 67 & 33 & - \\
\hline Inkare & 15 & 3,785 & 100 & - & - \\
\hline Centro Chocote & 27 & - & - & - & - \\
\hline \multicolumn{6}{|l|}{ San Martín } \\
\hline Chirikyacu & 80 & 5,492 & 11 & 8 & 81 \\
\hline Charapillo & 45 & 4,166 & 64 & 13 & 23 \\
\hline Chirik Sacha & 90 & 3,755 & 29 & 28 & 43 \\
\hline Santa Rosa & 12 & - & - & - & - \\
\hline Tornillo & 22 & - & - & - & - \\
\hline Juliampampa & 16 & - & - & - & - \\
\hline
\end{tabular}

Fuente: DRAU (2018), SICNA (2018)

o de protección, el Estado otorga derechos sobre ellas a las comunidades a través de un contrato de cesión en uso. Siete de las ocho comunidades tituladas de la muestra tienen parte de su territorio bajo cesión en uso. Hay solo una comunidad en Ucayali que fue titulada al $100 \%$, porque su título fue expedido en 1975, bajo la primera Ley de Comunidades Nativas que no establecía la diferenciación entre áreas en propiedad y áreas bajo cesión en uso. Las cuatro comunidades restantes están en proceso de titulación y no tienen la clasificación final de sus áreas. La superficie de los territorios bajo cesión en uso en las siete comunidades varía entre $14 \%$ a $89 \%$ (Cuadro 3). Las dos comunidades con más de $70 \%$ de sus territorios bajo cesión en uso están en San Martín.

Aunque es política del Estado zonificar los territorios indígenas en áreas aptas para actividades agropecuarias o aptas para actividades forestales o protección, este hecho es poco conocido por los pobladores de estas comunidades. Solo el 15\% de los y las informantes en la encuesta de hogares tenía conocimiento del término 'cesión en uso' y solo 5\% sabía que su comunidad contaba con áreas bajo este régimen, pero desconocía el concepto y la relación con su territorio. Al desagregar las respuestas por género, $75 \%$ de los hombres no conocía el concepto de cesión en uso, al igual que 99\% de las mujeres en Ucayali y 94\% de las mujeres en San Martín. Esta falta de comprensión de los procesos de titulación entre los beneficiarios y el Estado podría ser un elemento de confusión en el futuro.

\subsubsection{Derechos familiares en el contexto comunal}

A pesar de que las comunidades tienen territorios colectivos, tradicionalmente cada familia puede tener un área de uso permanente para producción agrícola. El área de uso familiar es definida como el terreno dentro del territorio comunal que cuenta con derechos consuetudinarios, adquiridos por tradición de uso o por asignación de la asamblea general. Estos derechos son exclusivos de la persona o familia mientras usan el área (quienes están empadronadas en la comunidad). 
En todas las comunidades, los derechos son transferibles entre miembros de una familia o hacia otros comuneros o comuneras. En algunas comunidades de San Martín, es posible transferir derechos de propiedad a personas externas, con la aprobación final de la asamblea comunal y con la consigna de que dichas personas sean incluidas en la comunidad. Por su parte, la comunidad, mediante la asamblea general, también puede transferir o asignar derechos de uso sobre la tierra a otro comunero, en caso de que el propietario original haya abandonado la comunidad y sus tierras.

Para los encuestados, hombres y mujeres, la intervención de la asamblea comunal en estas decisiones de transferencia de derechos es importante para asegurar que la persona que los adquiera no transgreda las políticas de la comunidad. En algunas comunidades hay casos en que personas externas, no nativas, se casaron con hombres o mujeres de la comunidad y adquirieron tierras. En esta situación, los estatutos comunales establecen de tres a cinco ańos de prueba, antes de aprobar el empadronamiento de los foráneos. En este estudio no se han reportado conflictos internos con estas personas.

\subsubsection{Percepciones sobre el bosque}

En cuanto a los bosques, el $45 \%$ del total de consultados afirmó que la condición actual de los bosques ha empeorado, en comparación con hace 20 años. Respecto a esta percepción, existe una diferencia resaltante entre ambas regiones. En Ucayali, el 61\% de encuestados opina que el bosque está en peores condiciones, mientras que en San Martín solo el 27\% comparte esta opinión. Esta diferencia es más marcada según la situación de la titulación. El 50\% de personas encuestadas en comunidades tituladas percibe que los bosques están en peores condiciones, mientras que sólo el $28 \%$ de las personas de comunidades no tituladas comparte esta percepción. Además, en San Martín las mujeres tienen opiniones más negativas sobre los cambios en la condición de los bosques, en comparación con los hombres (Figura 13).

Si bien existen grupos con opiniones diferentes, al analizar las razones se pueden hallar patrones para cada región. En ambas regiones, los y las encuestados describieron la situación del bosque en referencia al recurso maderable (existencia de árboles madereros). En San Martín, además

¿Cómo compara la situación actual de los bosques con la de hace 20 años?

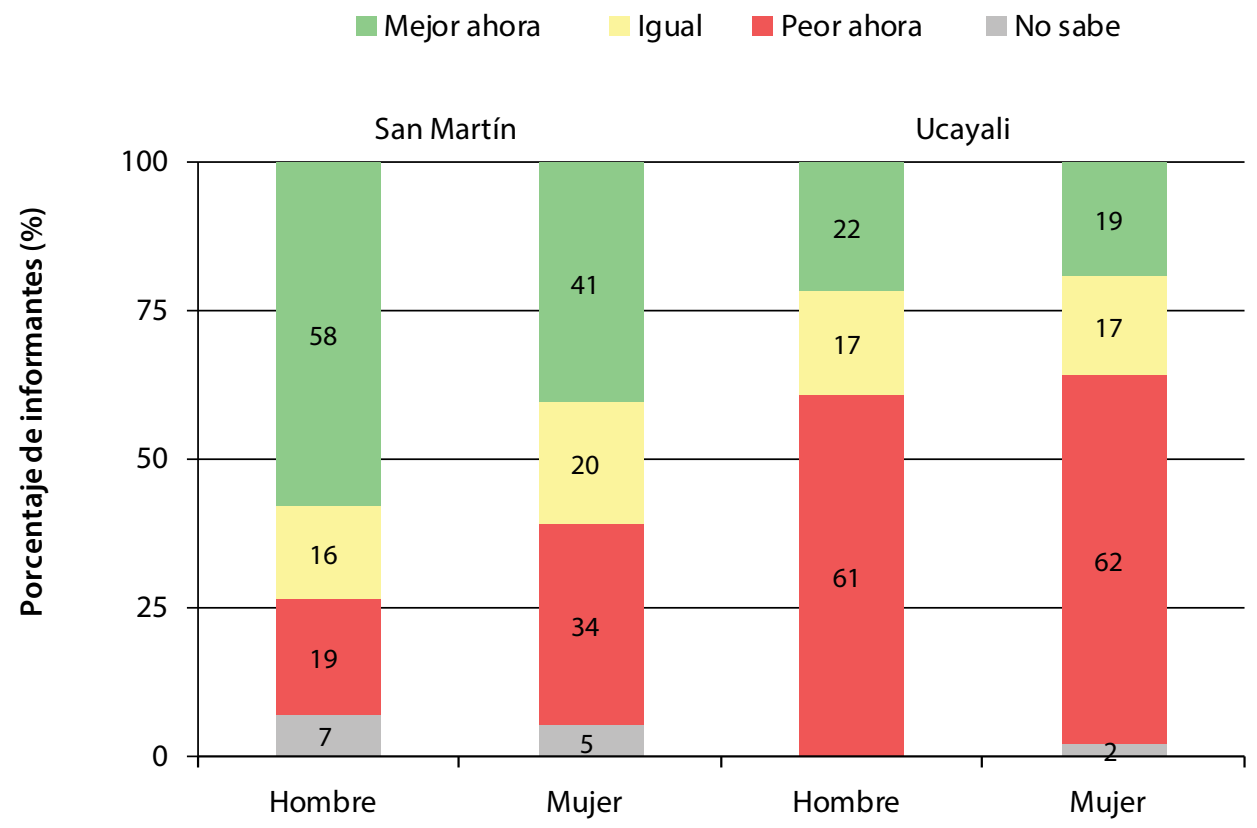

Figura 13. Percepciones sobre los cambios en la situación de los bosques en los últimos 20 años 
mencionaron que la escasez de recursos maderables se debe a su sobreexplotación en el pasado, por comuneros y foráneos, pero resaltaron que esta situación disminuyó por las restricciones que existen para la extracción de madera y por la formalización de los territorios comunales, pues disminuyen la tala ilegal. También señalaron otros factores particulares, por ejemplo, dos comunidades tituladas mencionaron al Programa Nacional de Conservación de Bosques como una iniciativa que mejoró la situación y la creación del Área de Conservación Regional (ACR) Cordillera Escalera como punto de inflexión a partir del cual mejoró la condición de los bosques. En Ucayali, donde las comunidades percibieron los bosques en una peor situación que en el pasado, los encuestados señalaron razones como la tala de árboles para madera y el establecimiento de parcelas agrícolas (por los mismos comuneros y en territorios colindantes), como las responsables.

Aunque la percepción sobre los cambios en la situación de los bosques es distinta entre ambas regiones, existe cierta similitud en relación a la influencia del proceso de titulación. Ante la pregunta de si la condición de los bosques ha mejorado desde el inicio del proceso de titulación, el 55\% está de acuerdo. Esta percepción es compartida por el $47 \%$ de los informantes en Ucayali y $64 \%$ en San Martín, una diferencia interesante, pero no significativa. Los resultados del estudio en Loreto y Madre de
Dios fueron muy similares: $62 \%$ dijo que había mejorado en Loreto y 48\% en Madre de Dios (Cruz et al. 2018). En San Martín y Ucayali, la explicación para estos cambios eran las mejoras en la vigilancia comunal (institucionalizada una vez que la comunidad es formalizada) y la reducción de las invasiones, así como de la extracción ilegal de recursos.

Pese a los cambios positivos, el poco conocimiento de los derechos adquiridos con el título y contrato de cesión en uso puede desencadenar una serie de eventos que inciten a la comunidad aprovechar sus recursos forestales de manera informal, afectando la sostenibilidad del bosque. Estas situaciones tienen como punto de partida el desconocimiento de los derechos y las normas relacionadas a las tierras forestales, debiendo ser tomado con mayor énfasis en los proyectos de titulación en curso y demás procesos relacionados.

\subsubsection{Percepciones sobre la seguridad alimentaria}

La seguridad alimentaria hace referencia al acceso de las comunidades a los alimentos y la sostenibilidad de estos en el tiempo. Según esta definición, se preguntó a los encuestados ‘ ¿Con qué frecuencia tuvo problemas para satisfacer las necesidades alimentarias de la familia en el último año?' De 338, 223 (66\%) respondieron que no tenían ningún problema para satisfacer sus necesidades alimentarias. Sin embargo, una tercera

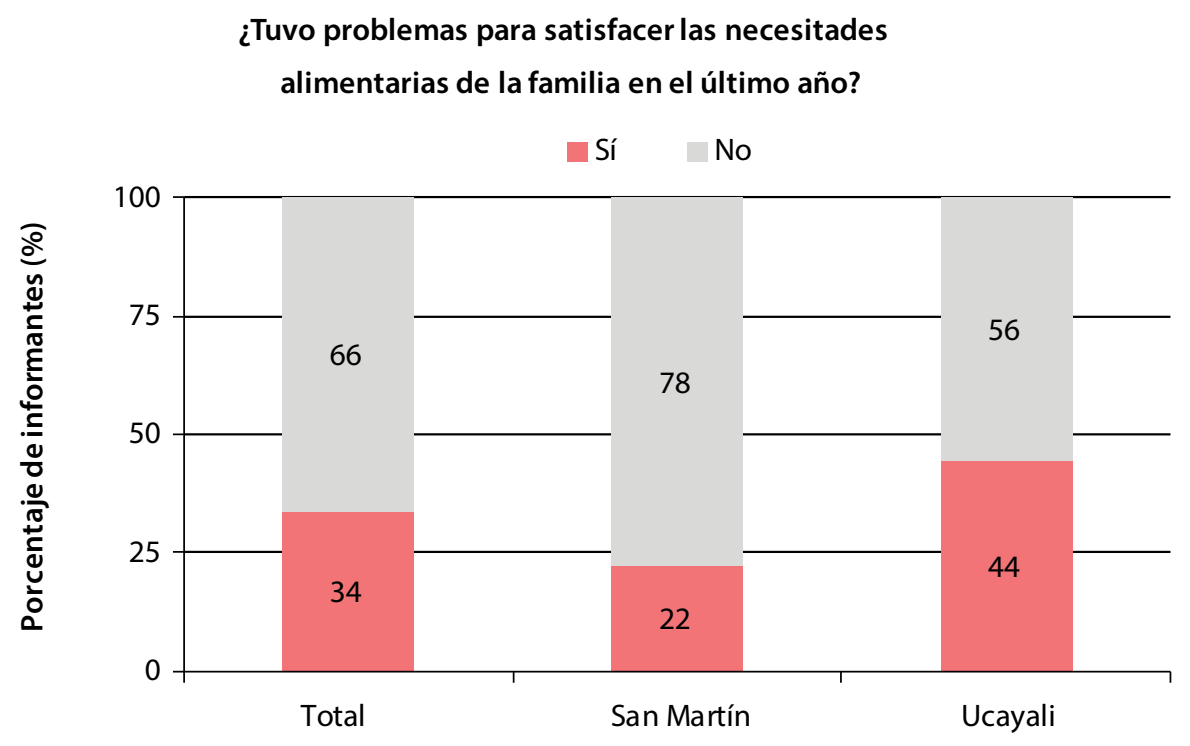

Figura 14. Satisfacción de las necesidades alimentarias por región en el último año 
parte (114 consultados o 34\%) sí reportaron haber tenido algún problema (Figura 14). De éstos últimos, el 28\% (34) mencionó problemas constantes durante el ańo y el resto, $(72 \%)$ una crisis en la alimentación durante 3 a 9 meses. Las razones de estas crisis son particulares a cada región. En Ucayali, donde el promedio de dificultades es más alto todavía (44\%), las comunidades dependen más de los recursos de caza y pesca por su lejanía de los mercados. De este modo, las crisis por falta de alimentos en esta región se deben principalmente a la escasez de estos recursos. En San Martín, donde estos problemas aparecen en menor número (22\%), las crisis se deben, según las y los encuestados, mayormente a una reducción en la productividad agrícola, que no permite cubrir la canasta familiar ni adquirir los alimentos necesarios para las familias.

$\mathrm{Al}$ analizar la muestra general y desagregarla por regiones y género, las mujeres tienen opiniones más negativas que los hombres sobre los problemas en torno a la seguridad alimentaria en el hogar, aunque en ambos grupos una mayor proporción opina que no tuvo problemas durante el último año (Figura 15). En las comunidades estudiadas, es notable la mayor responsabilidad asignada a las mujeres en relación a las necesidades alimentarias del hogar. Esta situación puede influir en una percepción más crítica o realista. Los resultados generales muestran que una mayor proporción de mujeres $(40 \%)$ en comparación con los hombres $(27 \%)$ opina que tuvo problemas para satisfacer las necesidades de alimentación del hogar durante el último año. $\mathrm{Y}$ una mayor proporción de hombres $(73 \%)$ que de mujeres $(60 \%)$ no cree haber tenido algún problema en el año. Además, una mayor cantidad de mujeres (13\%) que de hombres $(6 \%)$ opina que los problemas de seguridad alimentaria son frecuentes (todo el año). Es probable que las mujeres conozcan mejor la situación de la alimentación en el hogar.

En San Martín, 27\% de las mujeres y 18\% de los hombres informaron sobre algún problema para poder proveer de alimentos a sus familias en el último año. En Ucayali, la situación de las mujeres es aún más preocupante. Más de la mitad (53\%) de las encuestadas dice haber tenido algún problema de este tipo durante el último año, en comparación con el $36 \%$ de los hombres que comparte esta percepción.

Para comparar los cambios en el tiempo sobre la seguridad alimentaria, se preguntó ‘¿Cómo compararía su situación alimentaria actual con respecto a su situación hace 5 años?' Los resultados (Figura 16) muestran que la mitad de los hogares opina que no hubo cambios en la seguridad alimentaria, es decir esta sigue siendo la misma. En Ucayali existe una percepción más negativa que en San Martín: mientras que solo $10 \%$ de los consultados en San Martín respondió que la situación es peor ahora, en Ucayali estos alcanzaban el $44 \%$.

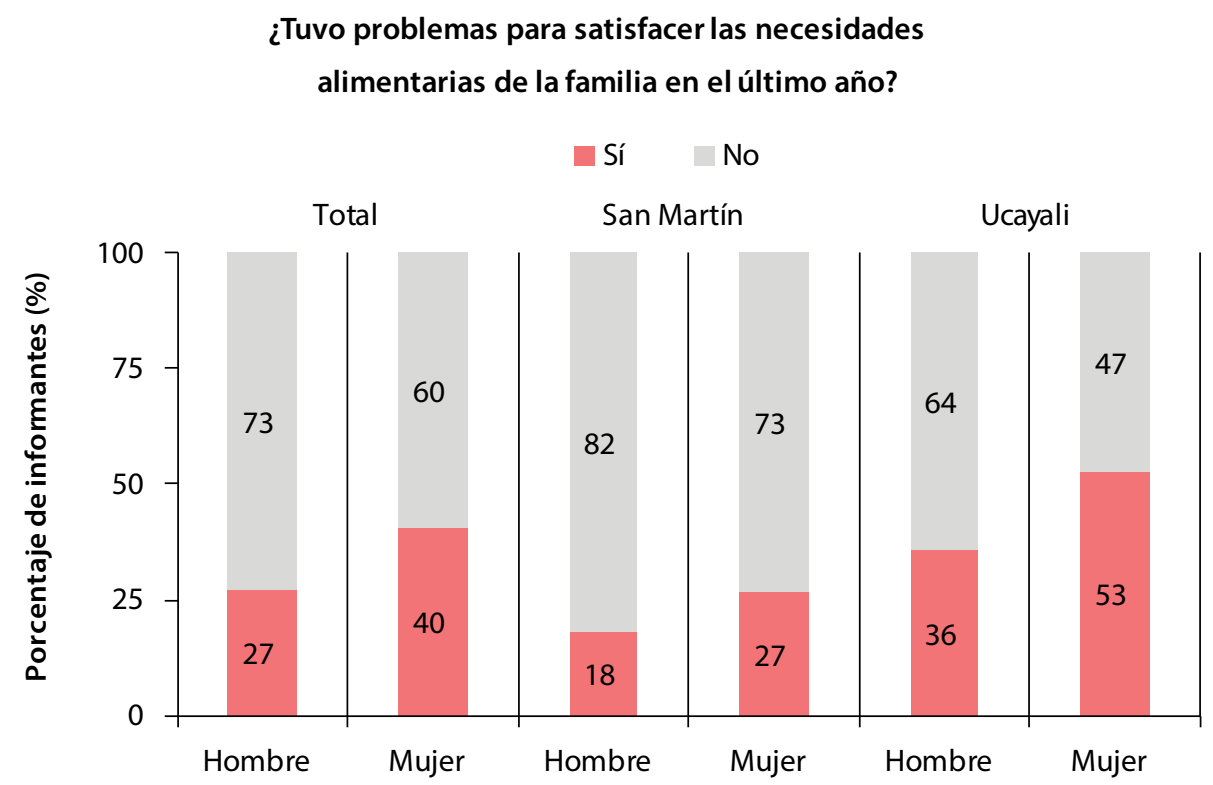

Figura 15. Satisfacción de las necesidades alimentarias por género en el último año 
¿Cambió su seguridad alimentaria en los últimos 5 años?

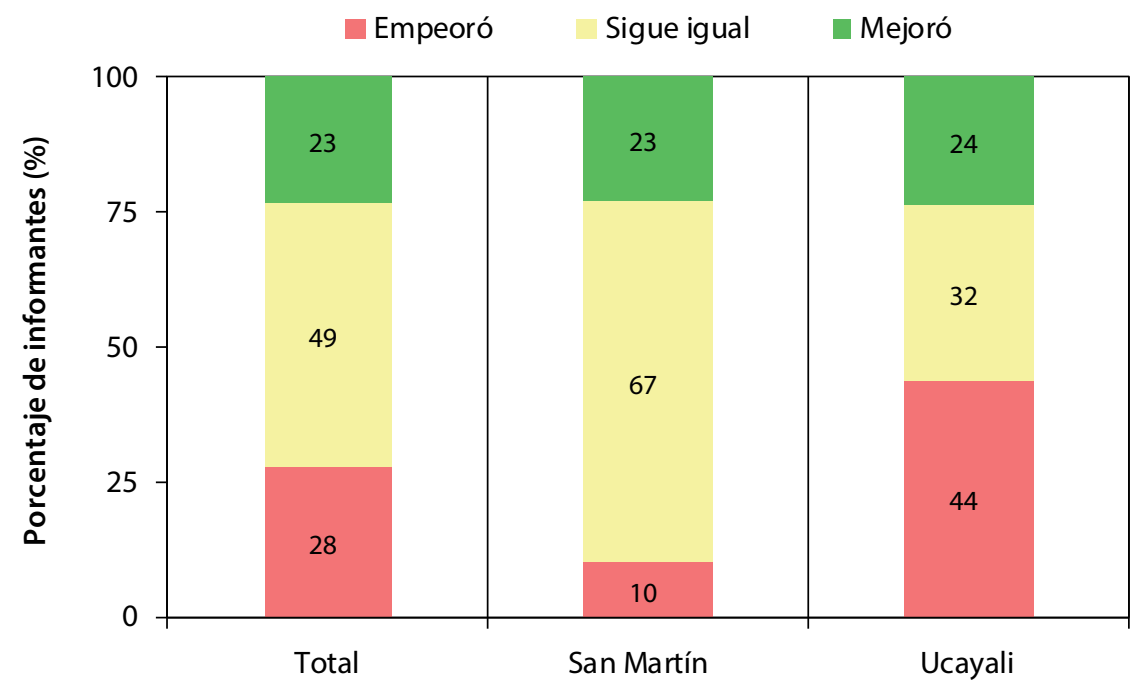

Figura 16. Cambios en la seguridad alimentaria por región en los últimos 5 años

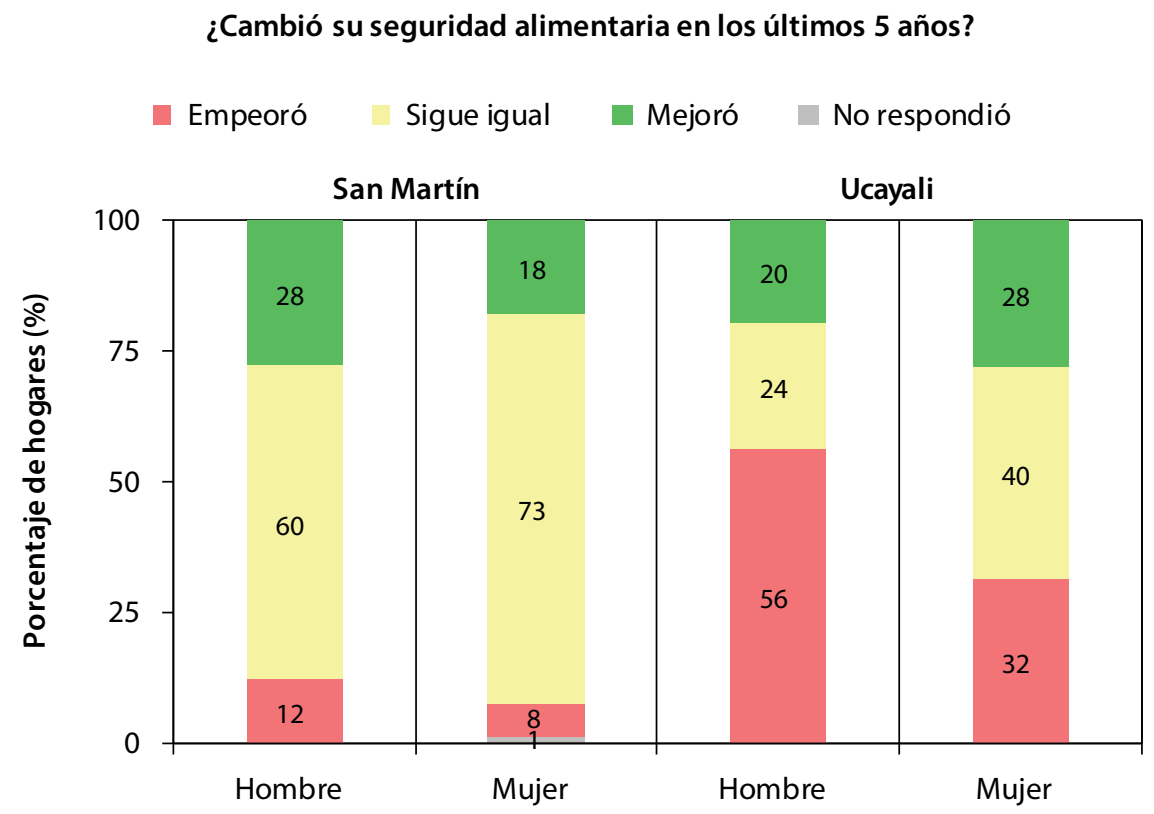

Figura 17. Cambios en la seguridad alimentaria por género en los últimos 5 años

Cuando se analiza la muestra general, los hombres tienen opiniones más negativas que las mujeres sobre los cambios en la seguridad alimentaria del hogar: una mayor proporción de mujeres (56\%) que de hombres (42\%) opina que la situación de la alimentación es la misma que hace 5 años. Un mayor número de hombres (35\%) que de mujeres (30\%) percibe que la situación empeoró. Una misma proporción en ambos géneros (24\%) opina que la situación mejoró. Sin embargo, al comparar los resultados en cada región (Figura 17), se observan situaciones contrastantes. En San Martín, los hombres son más optimistas acerca de estos cambios y en Ucayali sucede lo contrario. Estos resultados destacan nuevamente las diferencias en las percepciones sobre el bienestar del hogar entre hombres y mujeres. En San Martín, las mujeres son más críticas sobre los cambios en la 
seguridad alimentaria, lo que puede deberse a su mayor conexión con la administración de los ingresos del hogar y su relación estrecha con la seguridad alimentaria. En Ucayali, la mayor dependencia de los recursos del territorio influye en una percepción más negativa por parte de los hombres, lo que puede relacionarse a su mayor vínculo con la caza y pesca, que están disminuyendo, mientras que las mujeres administran más los alimentos obtenidos de las chacras.

En los hogares donde la situación alimentaria fue percibida como peor que hace 5 ańos, se preguntó a los entrevistados ‘QQue causó esta situación?’ El $59 \%$ opinó que fue la falta de recursos de caza y pesca. Otros porcentajes menores mencionaron la cosecha pobre de sus productos (14\%), la existencia de una situación económica precaria en el hogar $(8 \%)$, necesidades económicas no previstas $(4 \%)$ y desastres naturales (2\%). Al comparar los resultados de ambas regiones, es evidente nuevamente la mayor dependencia de las actividades de caza y pesca para la seguridad alimentaria de los hogares encuestados en Ucayali. Estos ponen mucho más énfasis en la escasez de recursos de caza y pesca (69\%) que los de San Martín (13\%). La importancia de la caza como actividad de los hombres principalmente podría explicar, al menos en parte, las diferencias en las respuestas por género en Ucayali.

También se preguntó sobre la mejora en la seguridad alimentaria: ‘QQué causó esta situación?’ De los 79 hogares que respondieron que esta había mejorado, el 46\% lo atribuyó a una buena cosecha de sus productos agrícolas. Esta razón recibe más énfasis en San Martín (68\%) que en Ucayali (26\%), debido al apoyo brindado a través de programas locales.

La existencia de subgrupos en algunas comunidades que perciben problemas con la seguridad alimentaria, debe ser una llamada de atención para los gobiernos, las federaciones y los líderes comunales, con el fin de consolidar el bienestar para todos los residentes de estas CCNN. Estos resultados reflejan las percepciones locales e indican posibles problemas con la seguridad alimentaria, no obstante, el tema merece un estudio más sistemático y detallado para entender la situación y sus causas. 


\section{Conclusiones}

Este informe detalló los resultados de la investigación aplicada "Titulación de

Comunidades Nativas - Avances y Desafíos” que tuvo por objetivo analizar el proceso de titulación y su impacto en doce comunidades nativas de tres pueblos indígenas en San Martín y Ucayali. Con el uso de tres métodos de recolección de datos, el equipo recabó información de un total de 684 informantes en las comunidades seleccionadas. La información obtenida describe algunas características de estas comunidades y de las percepciones de sus pobladores, que son relevantes en el contexto actual de las discusiones sobre cómo mejorar, simplificar y agilizar los procesos de titulación.

En general, las percepciones sobre los procesos de titulación en las comunidades seleccionadas fueron positivas ( $87 \%$ de los participantes de los grupos focales afirmaron estar satisfechos con la titulación). El grado de satisfacción fue similar entre ambas regiones y entre hombres y mujeres.

Por otro lado, los resultados también reflejan el poco conocimiento de las normas y la participación limitada de los comuneros (y sobre todo de las comuneras) en el desarrollo del proceso de titulación. En ambas regiones la participación femenina es menor a la de los hombres, no solo en el proceso de titulación, sino también en las otras reuniones organizadas en la comunidad. Esta situación puede estar relacionada a que los proyectos de titulación que actualmente se ejecutan, tienen plazos tan cortos, que muchas veces causan que las actividades destinadas al empoderamiento y participación de las comunidades en el proceso de titulación de sus territorios se lleven a cabo demasiado rápido y no logren estos objetivos. La limitada participación de la comunidad resalta el papel de la federación y de la junta directiva comunal en el seguimiento del proceso.
Tal vez, también debido a su participación reducida, los comuneros y comuneras conocen solamente el procedimiento de demarcación, pero no las otras etapas del proceso de titulación. En este contexto, la junta directiva comunal y las federaciones tienen el desafío de buscar maneras para asegurar una mayor participación y conocimiento de la población, en este y otros procesos, con especial énfasis en la población femenina. Además, es responsabilidad del Estado desarrollar estrategias de comunicación y metodologías adecuadas para asegurar la participación y el conocimiento de los y las comuneras acerca del desarrollo del proceso.

La débil participación y falta de conocimiento es incluso más evidente y preocupante en lo que respecta a la figura de los contratos de cesión en uso para las áreas forestales. Solo una pequeña parte de la población (15\%) los conoce, y este porcentaje es menor aun dentro de la población femenina (1\%). Esta situación puede generar discrepancias futuras entre las comunidades, la federación y el gobierno sobre los avances del proceso y los derechos adquiridos. Aunque esta situación fue explicada en los talleres de devolución de resultados, el tema necesita un mayor seguimiento por parte del Estado y de las federaciones para lograr un mejor diálogo con las comunidades y entendimiento del mecanismo y sus repercusiones.

Como es su objetivo, el proceso de titulación influye en gran medida en la seguridad de los derechos sobre la tierra de las CCNN, aunque este estudio solo pudo indagar las percepciones de algunas comunidades. En la encuesta de hogares, el 80\% de los 338 informantes percibió que, después de la titulación (o la demarcación), sus derechos estaban seguros, con mayor optimismo entre los hombres que entre las mujeres (por mínima diferencia, pero estadísticamente significativa). El 75\% sentía que sus derechos estaban protegidos ante disputas por el uso y acceso a la tierra. 
A pesar de las percepciones de seguridad en relación con los derechos de propiedad en la actualidad, existen indicadores de menor confianza sobre el futuro. Solo el $54 \%$ creía que nadie cuestionará sus derechos en el futuro, lo que refleja la preocupación de las comunidades frente a amenazas como las invasiones por terceros y la extracción ilícita de recursos forestales, en un contexto de débil protagonismo del Estado y pocas medidas de solución por parte de la comunidad para afrontarlas. Estos temores son mucho mayores en Ucayali que en San Martín, debido a la existencia de más conflictos, como resultado de la mayor inaccesibilidad de las comunidades, lo que genera una situación de abandono por parte del Estado.

La dinámica de los conflictos fue central en muchas de las entrevistas con grupos focales e informantes clave. Aunque solo el 19\% de hombres y mujeres encuestados estuvo involucrado en conflictos por tierras y recursos en el último año, esta respuesta fue tres veces más frecuente en Ucayali que en San Martín. Además, el 83\% de los conflictos reportados se dio con personas externas a la comunidad y menos de la mitad (47\%) fueron resueltos.

La percepción sobre la seguridad de los derechos a la tierra en las doce comunidades está influenciada por diversos factores. Además de la titulación, que aporta seguridad al territorio de manera simbólica y concreta, también influyen la ocupación física, la vigilancia comunal y la articulación entre la comunidad y su federación.

La inseguridad está vinculada a las invasiones y la extracción ilegal de recursos. Los conflictos asociados con estos problemas se exacerban al inicio del proceso de titulación debido a la incertidumbre causada por las negociaciones sobre acuerdos de colindancia, así como al desconocimiento de mecanismos para la mediación, que deben dar un rol más proactivo al Estado y a las federaciones para facilitar el diálogo con las comunidades.

Esta investigación ha documentado los medios de vida de las familias beneficiadas por el proceso de titulación, para entender cómo los sistemas de producción familiares están vinculados con el territorio en estas comunidades. Otras investigaciones han indagado cómo los procesos para establecer derechos de propiedad seguros se transforman, después de la titulación, en búsqueda de estrategias y opciones para mejorar el bienestar humano y aumentar los ingresos a través del aprovechamiento del territorio (ver Cronkleton et al. 2008; Pacheco et al 2011; Larson et al. 2019; Monterroso et al. 2019). En general, este estudio, ha identificado resultados mixtos sobre los medios de vida de la población. Por un lado, una percepción de satisfacción con la situación actual, pero también algunos indicadores preocupantes sobre la situación de algunas familias y posibles problemas de degradación de recursos.

La seguridad de la tierra influye en las condiciones de los medios de vida porque permite que las familias cubran sus necesidades a partir de un territorio claramente delimitado. En este contexto, el estudio identificó una economía poco diversificada, basada principalmente en la agricultura (la fuente de ingresos más importante para $70 \%$ de hogares). La producción agrícola es mayormente de subsistencia y es suplementada con la extracción de recursos naturales de los bosques, purmas y ríos. Existen opciones innovadoras como los cultivos agroforestales comerciales que son cada vez más populares (básicamente cacao o café en $27 \%$ de hogares), y tienen aparentemente mucho potencial para manejo forestal comercial, aunque actualmente no son fuentes de ingresos formales para muchos de los hombres y mujeres entrevistados.

Existe una gran diferencia entre la percepción que tienen las comunidades sobre su territorio (como algo integrado) y la percepción del Estado (que clasifica los territorios como propiedades agrícolas y áreas forestales bajo derechos de usufructo o cesión en uso). Esta disparidad tiene por lo menos dos aspectos: para las comunidades, no hay ninguna separación entre lo que está titulado y lo que se da en cesión en uso. Además, las federaciones indígenas promueven un concepto de territorio basado en la autodeterminación y cierta autonomía sobre todos los recursos naturales. Por lo que, hacen falta servicios y el apoyo del Estado para el desarrollo agrícola en las CCNN, en parte por la tendencia a ver la entrega del título como 'el final' del proceso. Sin embargo, la formalización de derechos en sí no está vinculada a la mejora de los medios de vida (ver Larson et al. 2019; Monterroso et al. 2019). 
En cuanto a la situación económica en las comunidades, 57\% de los hombres y mujeres encuestados no percibe mucha diferencia con sus vecinos y $29 \%$ piensa que su situación es mejor que la de otros en la comunidad. Sobre variaciones en los últimos cinco ańos, $36 \%$ de los comuneros y comuneras percibe cambios positivos en la economía de sus hogares y $51 \%$ no percibe cambios, aunque la gran mayoría considera su situación económica en general como regular o buena. Las comunidades en proceso de titulación tuvieron opiniones más optimistas, a la espera de un impacto positivo del proceso de titulación. La titulación también genera cambios en la percepción sobre los bosques y sus recursos. Según los hombres y mujeres encuestados, $55 \%$ cree que el proceso de titulación mejoró la condición de los bosques, principalmente porque redujo la ocurrencia de invasiones y extracción ilegal de recursos y permitió a la comunidad acceder a diversas iniciativas (proyectos agroforestales y Programa Bosques).

Estas percepciones relativamente buenas, o al menos estables, sobre la economía familiar contrastan con otros indicadores preocupantes. En general, las estimaciones de ingresos mensuales tienen un promedio de poco más de $S / 200$ soles peruanos por mes (aproximadamente USD 60) con algunos hogares que reportaron casi ningún ingreso monetario. Aunque tienen derechos más seguros sobre sus bosques, lo que ha generado una percepción de mejora, los y las informantes proveen resultados contradictorios respecto a que estos mismos bosques están más degradados que antes. El $45 \%$ de los y las consultados señala que las condiciones de los bosques son peores que hace 20 años, y en Ucayali $61 \%$ tiene esta opinión pesimista. Este resultado es muy relevante debido a la importancia de los bosques no solo como fuente de ingreso potencial, sino también por su importancia para la subsistencia en la actualidad. Este tema es relevante porque muchas de las familias encuestadas complementan su alimentación a través de la caza (68\% de hogares) y pesca (63\%), aunque la dependencia de estos recursos es mayor en Ucayali que en San Martín, por el acceso a los recursos y la falta de fuentes alternativas de alimento (mercados lejanos). Estas limitaciones están relacionadas con problemas aparentemente serios de seguridad alimentaria mencionados por $34 \%$ de los hogares, con una situación más grave en Ucayali (44\%) que en San Martín (22\%) en 2018.

En resumen, según los resultados del estudio sobre la interrelación entre la seguridad de la tierra, la economía familiar y el uso del territorio, el proceso de titulación representa para las doce CCNN una condición esencial para su desarrollo sostenible. Además se evidencia que si bien la titulación era o es un proceso necesario e importante, no resuelve por sí solo ninguno de los desafíos de las CCNN. Se necesita el apoyo del Estado, para enfrentar las amenazas externas y los conflictos que debilitan la seguridad de la tenencia, y para promover la conservación y gestión sostenible de los recursos naturales en sus territorios. Las comunidades también necesitan asistencia técnica para la gestión agroforestal según sus aspiraciones económicas y necesidades alimentarias. Además, el respaldo de sus federaciones es indispensable para fortalecer el seguimiento del proceso y mejorar la gobernanza local y regional. 


\section{Referencias}

Camero P y Gonzales I. 2018. Derechos de los Pueblos Indígenas en el Perú. Cartilla 3. Los Pueblos Indígenas y los procesos de reconocimiento y titulación de Comunidades Nativas. Lima: DAR y GIZ.

Cronkleton P y Larson A. 2015. Formalization and collective appropriation of space on forest frontiers: comparing communal and individual property systems in the Peruvian and Ecuadorian Amazon. Society \& Natural Resources, 28(5), pp.496-512.

Cronkleton P, Taylor P, Barry D, Stone-Jovicich $S$ y Schmink M. 2008. Environmental governance and the emergence of forest-based social movements. CIFOR Occasional Paper No. 49. CIFOR.

Cruz-Burga Z, Monterroso I, Larson AM, Valencia F y Saldaña J. 2018. El impacto de la formalización de los derechos sobre la tierra y el bosque: Perspectivas de comunidades en Madre de Dios y Loreto. CIFOR Infobrief \#221.

Larson AM, Monterroso I, Liswanti N, Herawati T, Banana A, Cantuarias P, Rivera K y Mwangi E. 2019. Models for formalizing customary and community forest lands: The need to integrate rights into rights and forest conservation goals. CIFOR Infobrief \#253.

Monterroso I, Larson AM, Gutiérrez Y, Quaedvlieg J y Jarama L. 2019. Guía Práctica para el Proceso de Titulación de Comunidades Nativas. CIFOR: Lima, Peru. https://www. cifor.org/library/7162/

Pacheco P, Barry D, Cronkleton P y Larson AM. 2011. The recognition of forest rights in Latin America: progress and shortcomings of forest tenure reforms. Society \& Natural Resources, 25(6), pp.556-571. 


\section{Anexo 1. Especies maderables cosechadas por informantes en San Martín y Ucayali}

\begin{tabular}{cll}
\hline Número & Especie & Nombre científico \\
\hline 1 & Ana caspi & Apuleia leiocarpa \\
2 & Bolaina & Guazuma ulmifolia \\
3 & Caimitillo & Chrysophyllum sp. \\
4 & Catahua & Hura crepitans \\
5 & Cedro & Cedrela sp. \\
6 & Copaiba & Copaifera sp. \\
7 & Cumala & Virola sp. \\
8 & Ishpingo & Amburana cearensis \\
9 & Lupuna & Ceiba pentandra \\
10 & Palo Sangre & Paramachaerium ormosioides \\
11 & Pashaco & Parkia sp. \\
13 & Quillobordon & Aspidosperma sp. \\
14 & Quinilla & Manilkara bidentata \\
15 & Sapote & Pouteria sp. \\
16 & Tornillo & Cedrelinga catenaeformis \\
\hline
\end{tabular}



El Gobierno de Perú está avanzando con el reconocimiento y formalización de los derechos territoriales de los pueblos indígenas de la Amazonía a través de, entre otros mecanismos, la titulación de tierras de las comunidades nativas (CCNN). Debido a la complejidad de este proceso, que involucra múltiples actores en diferentes niveles, profundizar el entendimiento de cómo se lleva a cabo la titulación en las comunidades, y cómo son percibidos sus impactos por los beneficiarios, resulta especialmente importante.

Este documento es una síntesis de los principales resultados de la investigación aplicada "Titulación de Comunidades Nativas - Avances y desafíos" que tuvo por objetivo analizar el proceso de titulación y su impacto en doce comunidades nativas de tres pueblos indígenas en San Martín y Ucayali. Con el uso de tres métodos de recolección de datos, el equipo recabó información de un total de 684 informantes en las comunidades seleccionadas. La información obtenida describe algunas características de estas comunidades y de las percepciones de sus pobladores, que son relevantes en el contexto actual de las discusiones sobre cómo mejorar, simplificar y agilizar los procesos de titulación.

En general, las percepciones sobre los procesos de titulación en las comunidades seleccionadas fueron positivas. Como es su intención, el proceso de titulación influye en gran medida en la seguridad de los derechos sobre la tierra de las CCNN. En resumen, según los resultados del estudio sobre la interrelación entre la seguridad de la tierra, la economía familiar y el uso del territorio, el proceso de titulación representa para las doce CCNN una condición esencial para su desarrollo sostenible. Además se evidencia que si bien la titulación era o es un proceso necesario e importante, no resuelve por sí solo ninguno de los desafíos de las CCNN. Se necesita el apoyo del Estado, para enfrentar las amenazas externas y los conflictos que debilitan la seguridad de la tenencia, y para promover la conservación y gestión sostenible de los recursos naturales en sus territorios. Las comunidades también necesitan asistencia técnica para la gestión agroforestal según sus aspiraciones económicas y necesidades alimentarias. Además, el respaldo de sus federaciones es indispensable para fortalecer el seguimiento del proceso y mejorar la gobernanza local y regional.

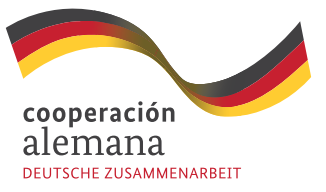
desarrollando las capacidades de sus socios y dialogando activamente con todos los actores involucrados, para informar sobre las políticas y las prácticas que afectan a los bosques y a las personas. CIFOR es un centro de investigación CGIAR y lidera su Programa de Investigación sobre Bosques, Árboles y Agroforestería (FTA por sus siglas en inglés). Nuestra sede central se encuentra en Bogor, Indonesia, y contamos con oficinas en Nairobi, Kenia; Yaundé, Camerún; Lima, Perú, y Bonn, Alemania. 